\title{
Solar fuel processing efficiency for ceria redox cycling using alternative oxygen partial pressure reduction methods
}

\author{
Meng Lin, Sophia Haussener* \\ Laboratory of Renewable Energy Science and Engineering, EPFL, Station 9, 1015 Lausanne, Switzerland
}

\section{A R T I C L E I N F O}

\section{Article history:}

Received 15 April 2015

Accepted 2 June 2015

Available online 8 July 2015

\section{Keywords:}

Solar fuels

Ceria redox cycling

Thermodynamics

Oxygen scavenger

Vacuum pump

Sweep gas

\begin{abstract}
A B S T R A C T
Solar-driven non-stoichiometric thermochemical redox cycling of ceria for the conversion of solar energy into fuels shows promise in achieving high solar-to-fuel efficiency. This efficiency is significantly affected by the operating conditions, e.g. redox temperatures, reduction and oxidation pressures, solar irradiation concentration, or heat recovery effectiveness. We present a thermodynamic analysis of five redox cycle designs to investigate the effects of working conditions on the fuel production. We focused on the influence of approaches to reduce the partial pressure of oxygen in the reduction step, namely by mechanical approaches (sweep gassing or vacuum pumping), chemical approaches (chemical scavenger), and combinations thereof. The results indicated that the sweep gas schemes work more efficient at nonisothermal than isothermal conditions, and efficient gas phase heat recovery and sweep gas recycling was important to ensure efficient fuel processing. The vacuum pump scheme achieved best efficiencies at isothermal conditions, and at non-isothermal conditions heat recovery was less essential. The use of oxygen scavengers combined with sweep gas and vacuum pump schemes further increased the system efficiency. The present work can be used to predict the performance of solar-driven non-stoichiometric redox cycles and further offers quantifiable guidelines for system design and operation.
\end{abstract}

๑) 2015 Elsevier Ltd. All rights reserved.

\section{Introduction}

The direct solar-driven processing of fuels by the thermochemical splitting of $\mathrm{H}_{2} \mathrm{O}$ and $\mathrm{CO}_{2}$ into $\mathrm{H}_{2}$ and $\mathrm{CO}$, a mixture called syngas, is a promising pathway for renewable fuel synthesis. The syngas can further be converted into liquid fuels through a conventional Fischer-Tropsch process effectively providing a direct approach for liquid solar fuel processing [1,2]. This approach exhibits a small environmental impact, allows for direct solar energy storage, and permits using conventional energy distribution infrastructure [1-4]. Direct $\mathrm{H}_{2} \mathrm{O}$ and $\mathrm{CO}_{2}$ thermolysis is challenging since temperatures above $2700 \mathrm{~K}$ are needed for reasonable reaction convergence $[5,6]$, and efficient high temperature gas separation of a (possible explosive) mixture is required. Thermochemical multi-step cycles have been proposed to circumvent these drawbacks [1,7-9]. Particularly two-step, non-volatile metal oxidebased cycles show promise in avoiding gas separation issues, working at lower temperatures compared to direct thermolysis,

\footnotetext{
* Corresponding author. Tel.: +4121693 3878.

E-mail address: sophia.haussener@epfl.ch (S. Haussener).
}

enabling relatively simple design and operation, and theoretically achieving high solar-to-fuel efficiencies [10-14]. Ceria nonstoichiometric redox cycling has attracted interest due to its nonvolatile characteristics even at high operating temperature, fast kinetics causing high hydrogen generation rates $[12,15,16]$, theoretical high solar-to-fuel efficiencies [13,14,17], and practical demonstration of reasonable efficiencies in working prototypes [18-21]. The two steps water and $\mathrm{CO}_{2}$ splitting reactions through non-stoichiometric ceria cycling are given as $\left(\Delta \delta=\delta_{\text {red }}-\delta_{\text {ox }}\right)$

$$
\begin{aligned}
& \mathrm{CeO}_{2-\delta_{\mathrm{ox}}} \rightarrow \mathrm{CeO}_{2-\delta_{\text {red }}}+\frac{\Delta \delta}{2} \mathrm{O}_{2}, \\
& \mathrm{CeO}_{2-\delta_{\text {red }}}+\Delta \delta \mathrm{H}_{2} \mathrm{O} \rightarrow \mathrm{CeO}_{2-\delta_{\mathrm{ox}}}+\Delta \delta \mathrm{H}_{2}, \\
& \mathrm{CeO}_{2-\delta_{\text {red }}}+\Delta \delta \mathrm{CO}_{2} \rightarrow \mathrm{CeO}_{2-\delta_{\mathrm{ox}}}+\Delta \delta \mathrm{CO}
\end{aligned}
$$

The endothermic reduction step, eq. (1), operates with reasonable conversion at temperatures ranging between $1400 \mathrm{~K}$ and $2100 \mathrm{~K}$. The exothermic oxidation reactions, eqs. (2) and (3), favor lower temperatures in order to ensure a complete oxidation of ceria [12] with a typical temperature range of around $700 \mathrm{~K}-1100 \mathrm{~K}$. The 
temperature difference between the two steps requires solid phase heat recovery in order to maintain a high solar-to-fuel efficiency [14], which is difficult to realize and increases the system complexity. Therefore, isothermal cycling has been proposed $[16,22,23]$.

Thermodynamic evaluations of the performance of ceria redox cycling have been reported in Refs. [3,13,14,17,24]. Panlener et al. studied the reaction enthalpy of non-stoichiometric ceria in a large range of temperatures and pressures by thermogravimetric measurements [25]. Riess et al. [26] investigated the specific heat of ceria by an adiabatic temperature scanning calorimeter. Lapp et al. [15] performed a parametric thermodynamic analysis of a ceriabased cycling scheme using an ideal mixing model and sweep gassing to maintain a low oxygen concentration atmosphere for the reduction step. They found that effective solid phase heat recovery was crucial in achieving solar-to-fuel efficiencies above $10 \%$. Bader et al. [13] demonstrated numerically that isothermal cycling of ceria was possible at the expense of reduced system performance. Sweep gas was used to reduce the oxygen partial pressure in the reduction chamber, gas phase heat recovery was assumed, and plug flow reactor models in counter flow arrangements were employed in both chambers. Gas phase heat recovery with effectiveness above $95.5 \%$ was required for solar-to-fuel efficiencies above $10 \%$. The energy penalty introduced through the use of immense amounts of sweep gas pointed to the need for alternative methods to reduce the oxygen partial pressure during the reduction reaction. Ermanoski et al. [17] showed for the non-isothermal cycling of ceria using ideal mixing in both reaction chambers that the efficiency of the process could be increased by using vacuum pumping schemes for the reduction of the oxygen partial pressure. It is unclear whether this conclusion applies to isothermal operation and whether a further decrease of the oxygen partial pressure in the reduction chamber through non-mechanical methods is required for competitive solar-to-fuel efficiencies provided the use of solid-solid and gas-gas heat recovery components with realistic heat exchange effectiveness.

We developed a thermodynamic model for evaluating optimal operating conditions (system pressure, oxygen partial pressure, reduction temperature, oxidation temperature, heat recovery, and irradiation concentration ratio) for various system configurations of non-stoichiometric cycling of ceria using concentrated solar irradiation. Particularly, we focused on the reduction step and on the incorporation of alternative methods - mechanical and chemical for reducing the oxygen partial pressure. The understanding of the influence of working conditions, component choices, and system configurations on system performance is required for the determination of the optimal operation conditions and design of practical system configurations for increased solar fuels processing efficiencies.

\section{Thermodynamic model}

\subsection{Model development}

Five thermochemical fuel production systems investigated are depicted in Fig. 1. They differed in their approaches to reduce the oxygen partial pressure in the reduction chamber, namely: three mechanical schemes using i) sweep gas (scheme a) [14,15], ii) vacuum pump (scheme b) [18], and iii) the combination thereof (scheme d); and two combined mechanical-chemical schemes using i) sweep gas and a chemical scavenger (scheme c), and ii) using the combination of sweep gas, vacuum pump, and a chemical scavenger (scheme e). All five systems used two continuously and simultaneously operating reaction chambers for the separated reduction and oxidation reactions. The systems incorporated two heat exchanges to recover the heat from the exhaust (sweep gas and products). Solid phase heat recovery was incorporated between the reduced and oxidized ceria streams.

In scheme (a) inert gas was used to sweep away the produced oxygen during the reduction and correspondingly maintaining a desired oxygen partial pressure at the entrance (process 3-4). The sweep gas flow and the ceria flow was considered in a counterflow arrangement [13], i.e. the pressure and temperature will stay constant while the concentration of oxygen and the $\delta$ of ceria vary only in axial direction. Compared to the ideal mixing flow design used in Refs. $[15,18]$, the counterflow arrangement maximized the $p_{\mathrm{O}_{2}}$ in the sweep gas at the outlet of the reduction chamber and minimized the $p_{\mathrm{O}_{2}}$ at the outlet of the oxidation chamber, resulting in a reduced sweep gas demand and reactant input. The inert gas was preheated in a heat exchanger and further heated by concentrated solar energy to the reduction temperature, $T_{\text {red, }}$, before entering the reduction chamber. The states 5 to 8 described a full, closed ceria cycle. The ceria was cooled to the oxidation temperature, $T_{\mathrm{ox}}$, in the process 5-6 while rejecting $Q_{\text {ceria }}$ (not needed for isothermal operation), and isothermally reacted with the oxidizing agents $\left(\mathrm{H}_{2} \mathrm{O}, \mathrm{CO}_{2}\right)$ in the oxidation chamber during the process 6-7. Finally, the ceria temperature was heated to $T_{\text {red }}$ (process 7-8) and then isothermally reduced in the reduction chamber (process 8-5). The oxidizer was preheated in the heat exchanger by effluent and further heated to $T_{\mathrm{ox}}$ by concentrated solar energy (process 10-11). Since the oxidation reaction was an exothermic process, the energy needed to heat the oxidizer from $T_{10}$ to $T_{11}$ may be less than the heat released by the reaction and hence a heat exchanger was used for further exhaust cooling after heat recovery (process 13-14).

The processes of scheme (b) were similar to the processes in scheme (a) concerning the oxidation process and the ceria cycling process. However, the oxygen generated in the reduction chamber was not swept away by inert gas. Instead a vacuum pump was employed continuously removing the produced oxygen during the reduction and maintaining a desired oxygen partial pressure in the chamber.

In scheme (c), sweep gassing was combined with a chemical oxygen scavenger (process $1^{\prime}-2^{\prime}$ ) in which the oxygen in the sweep gas is reacted with an active metal (e.g. magnesium) to further reduce the oxygen partial pressure. Magnesium has been reported to be an alloying element in metals industries acting an important chemical oxygen scavenger which is widely used is large scale metal alloy production $[27,28]$. Magnesium oxide can be recycled through various thermochemical and electrochemical processes which are commonly used for industrial magnesium production [29].

Scheme (d) was a combination of both mechanical approaches, namely sweep gassing and vacuum pump. Scheme (e) combined scheme (d) with the chemical scavenger.

Additional assumptions used in the model were: $i$ ) the system was evaluated at steady state, ii.a) for scheme (a), counterflow arrangement was assumed for both reduction and oxidation chamber, ii.b) for scheme (b), counterflow arrangement was assumed in the oxidation chamber and the oxygen was uniformly distributed in the reduction chamber, iii) gases were modeled as ideal gases, and $i v$ ) temperatures of the reactants in the reduction and oxidation chambers were considered constant and uniform.

Additionally, we used ideal mixing models for the reduction and oxidation chambers to account for a less favorable reaction chamber design configuration. The ideal mixing model considered the equilibrium $p_{\mathrm{O}_{2}}$ that was created by the water at $T_{\mathrm{Ox}}$, influencing the non-stoichiometry at oxidation. In this case, the $p_{\mathrm{O}_{2}}$ in the oxidation chamber was determined by optimizing it for largest cycle efficiency while ensuring it was smaller than $p_{\mathrm{O}_{2}}$ of water dissociation at $T_{\mathrm{ox}}$. 

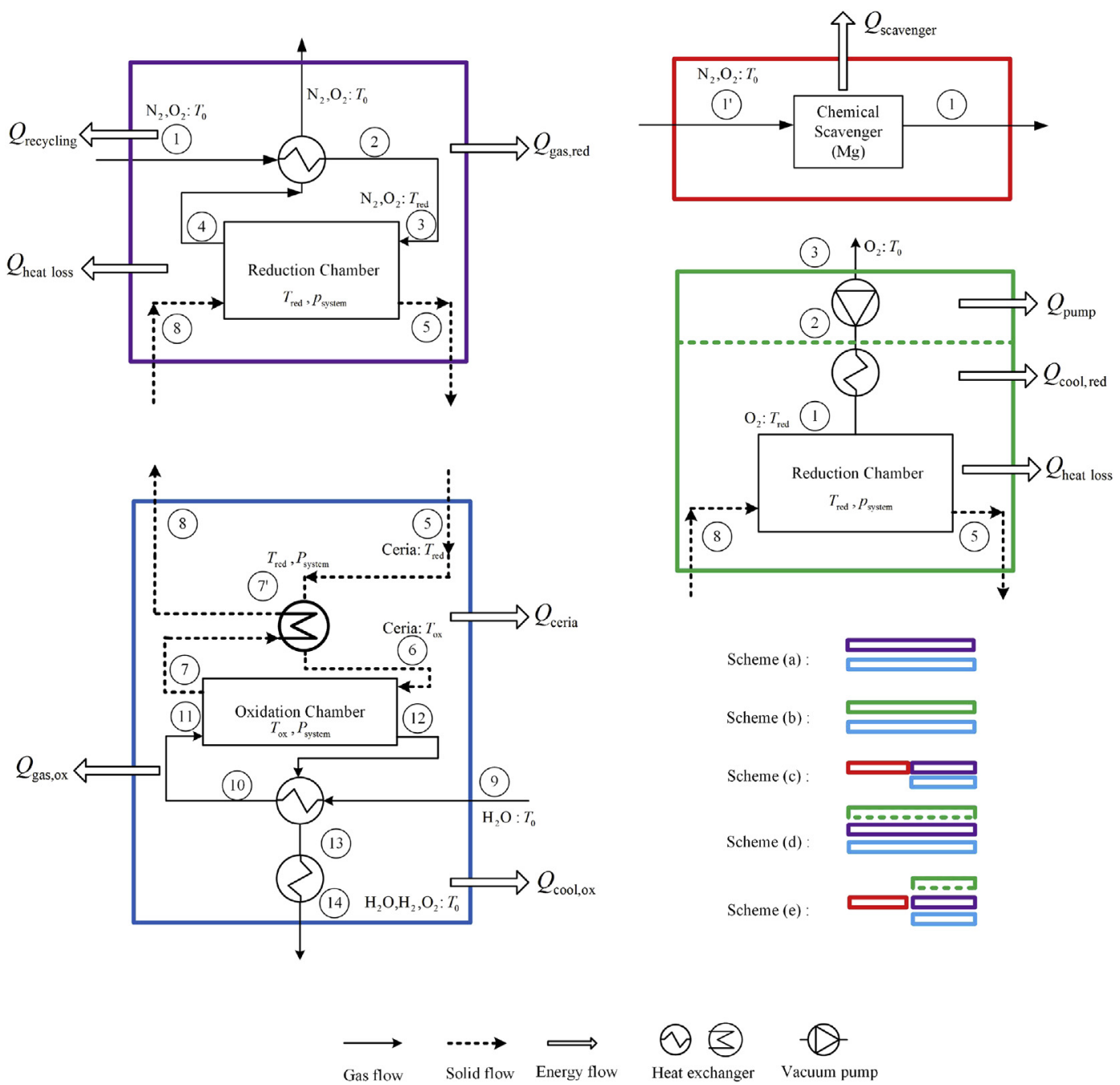

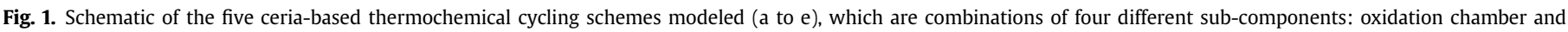

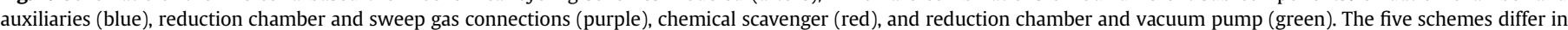

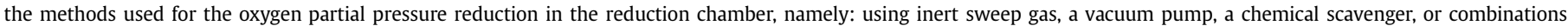
thereof.

The steady state energy balance for the modeled system was given by

$$
\begin{aligned}
\dot{Q}_{\text {solar }}= & \dot{Q}_{\text {heat loss }}+\dot{Q}_{\text {react }}+\dot{Q}_{\text {gas }, \text { red }}+\dot{Q}_{\text {gas }, \text { ox }}+\dot{Q}_{\text {cool }, \text { ox }} \\
& +\dot{Q}_{\text {cool,red }}+\dot{Q}_{\text {ceria }}+\dot{Q}_{\text {pump }}+\dot{Q}_{\text {recycling }}+\dot{Q}_{\text {scavenger }}
\end{aligned}
$$

$\dot{Q}_{\text {solar }}$ was the solar energy incident on a blackbody receiver with a certain aperture area for concentrated solar irradiation $\left(\dot{Q}_{\text {solar }}=A_{\mathrm{ap}} C I\right)$. Note that the last three terms on the right hand side $\left(\dot{Q}_{\text {pump }}, \dot{Q}_{\text {recycling }}, \dot{Q}_{\text {scavenger }}\right)$ are not all concurrently required for all schemes, as detailed below. The heat losses accounted for the radiation heat loss from the aperture, and conduction and convection losses through the cavity walls. The latter were assumed to be a constant fraction, $f$, of the total solar energy captured by the cavity and assumed 20\% according to experimental observations [30]. Hence, the heat losses were given by

$\dot{Q}_{\text {heat loss }}=\dot{Q}_{\text {rad }}+f\left(\dot{Q}_{\text {solar }}-\dot{Q}_{\text {rad }}\right)=(1-f) A_{\text {ap }} \sigma T_{\text {red }}^{4}+f \dot{Q}_{\text {solar }}$.
The power utilized for the chemical reaction was the sum of the chemical reactions in the reduction and oxidation chambers,

$\dot{Q}_{\text {react }}=\dot{Q}_{\text {react }, \mathrm{ox}}+\dot{Q}_{\text {react,red }}=\dot{n}_{\mathrm{H}_{2}} \Delta h_{\mathrm{H}_{2} \mathrm{O} \text {,react }}\left(T_{\mathrm{ox}}\right)$,

where $\dot{Q}_{\text {react,red }}=-\dot{Q}_{\text {react,ox }}=\dot{n}_{\text {ceria }} / 2 \int_{\delta_{\text {ox }}}^{\delta_{\text {red }}} \Delta h_{\mathrm{O}_{2}}(\delta) \mathrm{d} \delta$. We focused our investigations on the splitting of water. Nevertheless, the splitting of $\mathrm{CO}_{2}$ or a combination of water and $\mathrm{CO}_{2}$ can be studied analogously and selected results are presented in the supporting information.

In scheme (a), the sweep gas was preheated in a heat exchanger (with recovery effectiveness, $\varepsilon_{g}$ ) by heat of the effluent,

$$
\begin{aligned}
\dot{Q}_{\text {gas }, \text { red }}= & \left(1-\varepsilon_{g}\right) \dot{n}_{\mathrm{N}_{2}, 1}\left[h_{\mathrm{N}_{2}}\left(T_{\text {red }}\right)-h_{\mathrm{N}_{2}}\left(T_{0}\right)\right] \\
& +\left(1-\varepsilon_{g}\right) \dot{n}_{\mathrm{O}_{2}, 1}\left[h_{\mathrm{O}_{2}}\left(T_{\text {red }}\right)-h_{\mathrm{O}_{2}}\left(T_{0}\right)\right],
\end{aligned}
$$

before entering the reduction chamber where the final $T_{\text {red }}$ was achieved through part of the solar irradiation. $\dot{n}_{\mathrm{O}_{2}, 1}$ was the molar flow of oxygen in the inert gas before entering the reduction chamber. 
$\dot{Q}_{\text {gas,red }}=0$ in scheme (b) since no sweep gas was introduced. However, the oxygen produced in the ceria reduction process was continuously pumped out by a vacuum pump and, for practical reasons, has to be cooled before entering the pump. The energy loss due to cooling is calculated as

$\dot{Q}_{\text {cool,red }}=\left(\dot{n}_{\mathrm{O}_{2}, 4}-\dot{n}_{\mathrm{O}_{2}, 1}\right)\left[h_{\mathrm{O}_{2}}\left(T_{\text {red }}\right)-h_{\mathrm{O}_{2}}\left(T_{0}\right)\right]$.

Similarly, the energy required for the heating of the oxidizer was given as

$$
\begin{aligned}
\dot{Q}_{\text {gas }, \mathrm{ox}}= & \left(\dot{n}_{\mathrm{H}_{2} \mathrm{O}, 9}-\varepsilon_{g} \dot{n}_{\mathrm{H}_{2} \mathrm{O}, 12}\right)\left[h_{\mathrm{H}_{2} \mathrm{O}}\left(T_{\mathrm{ox}}\right)-h_{\mathrm{H}_{2} \mathrm{O}}\left(T_{0}\right)\right] \\
& -\varepsilon_{g} \dot{n}_{\mathrm{H}_{2}, 12}\left[h_{\mathrm{H}_{2}}\left(T_{\mathrm{ox}}\right)-h_{\mathrm{H}_{2}}\left(T_{0}\right)\right]-\varepsilon_{g} \dot{n}_{\mathrm{O}_{2}, 12}\left[h_{\mathrm{O}_{2}}\left(T_{\mathrm{ox}}\right)\right. \\
& \left.-h_{\mathrm{O}_{2}}\left(T_{0}\right)\right] .
\end{aligned}
$$

The oxidation reaction was slightly endothermic which can lead to excessive heat in the oxidation chamber. In this case cooling was considered in the energy balance by

$\dot{Q}_{\text {cool,ox }}=\dot{Q}_{\text {react,ox }}-\dot{Q}_{\text {gas }, 0 x}$.

For non-isothermal operation, ceria needed to be heated from the oxidation to the reduction temperature,

$\dot{Q}_{\text {ceria }}=\dot{n}_{\text {ceria }} \int_{T_{\mathrm{ox}}}^{T_{\text {red }}} c_{p, \text { ceria }} \mathrm{d} T$.

Similarly, the ceria needed to be cooled from the reduction to the oxidation temperature when exiting the reduction chamber. Potentially, the rejected heat during this cooling step can be partially recovered in a solid-solid heat exchanger (with a effectiveness, $\left.\varepsilon_{S}\right)$ in order to minimize the required $\dot{Q}_{\text {ceria }}$ for the solid heating step (eq. (11)).

The pumping work for the cycling of the gas and solid reactants and products in both reaction chambers and through the piping was neglected in all schemes. The pumping work required in scheme (b) to remove the generated oxygen in the reduction process was calculated by

$\dot{Q}_{\text {pump }}=\frac{W_{\text {pump }}}{\eta_{\mathrm{t}} \eta_{\text {pump }}}=\frac{\dot{n}_{\mathrm{O}_{2}, 1} R T_{0}}{\eta_{\mathrm{t}} \eta_{\text {pump }}} \ln \frac{p_{0}}{p_{\mathrm{O}_{2}, 1}}$

where $W_{\text {pump }}$ was the pumping work for moving the oxygen stream out of reduction chamber, $\eta_{\mathrm{t}}$ was the heat-to-electricity efficiency, $\eta_{\text {pump }}$ was the electricity-to-pumping work efficiency, $p_{0}$ was the ambient pressure, and $p_{\mathrm{O}_{2}}$ was the partial pressure of oxygen in the reduction chamber.

The energy for recycling the sweep gas, $\dot{Q}_{\text {recycling, occupied less }}$ than $1 \%$ of the total solar energy input [13] and was neglected in the current study. The recycling energy of the chemical scavenger is given by

$\dot{Q}_{\text {scavenger }}=\frac{\dot{n}_{\mathrm{N}_{2}, 1^{\prime}}\left(p_{\mathrm{O}_{2}, 2^{\prime}}-p_{\mathrm{O}_{2}, 1^{\prime}}\right)}{p_{0}} \dot{Q}_{\mathrm{Mg}, \mathrm{pr}}$,

where the $\dot{Q}_{\mathrm{Mg} \text {,pr }}$ was the total energy need to produce $1 \mathrm{~mol}$ of magnesium, which was obtained from industrial databases [31].

The molar flow rates of all streams at each state were obtained by solving the mass balance in both chambers considering chemical equilibrium, counterflow or ideal mixing arrangement, respectively, and a two-step oxidation reaction including the water thermolysis and oxidation of reduced ceria by oxygen [13]. $\delta_{\text {red }}$ was determined by the $p_{\mathrm{O}_{2}}$ and $T_{\text {red }}$ at the inlet of the reduction chamber, and $\delta_{\mathrm{ox}}$ was obtained according to the $p_{\mathrm{O}_{2}}$ and $T_{\mathrm{ox}}$ at the inlet of the oxidation chamber. $p_{\mathrm{O}_{2}}$ at the inlet of the oxidation chamber only depended on $T_{\mathrm{ox}}$ and hence also $\delta_{\mathrm{ox}}$ was only a function of $T_{\mathrm{ox}}$.

The non-stoichiometry coefficient, $\delta$, for the undoped ceria reduction and oxidation reaction under various conditions was determined using the experimental data of Panlener et al. [25], in which experiments for oxygen partial pressures and temperatures ranging from $10^{-22}$ atm to $10^{-2}$ atm and $1023 \mathrm{~K}-1774 \mathrm{~K}$, respectively, with $\delta$ varying from 0.00107 to 0.27 were performed. The values of $\delta$ were calculated for given temperatures and $p_{\mathrm{O}_{2}}$ by,

$\Delta g_{\mathrm{O}_{2}}(\delta, T)=\Delta h_{\mathrm{O}_{2}}(\delta)-T \Delta s_{\mathrm{O}_{2}}(\delta)=R T \ln \frac{p_{\mathrm{O}_{2}}}{p_{0}}$.

The specific heat of nonstoichiometric ceria was estimated by the specific heat of cerium dioxide without considering the impact of phase transformations [26].

\subsection{Definitions}

Three performance indicators were used in this study: $i$ ) the solar-to-fuel efficiency, ii) water utilization factor, and iii) hydrogen productivity. The solar-to-fuel efficiency, $\eta$, was defined as

$\eta=\frac{\dot{n}_{\mathrm{H}_{2}, 12} \mathrm{HHV}_{\mathrm{H}_{2}}}{\dot{Q}_{\text {solar }}}$.

The water utilization factor, $f_{\mathrm{w}}$, was the ratio between the amount of hydrogen produced and the total water input into the oxidation chamber,

$f_{\mathrm{w}}=\frac{\dot{n}_{\mathrm{H}_{2}, 12}}{\dot{n}_{\mathrm{H}_{2} \mathrm{O}, 9}}$

$f_{\mathrm{w}}$ indicated the efficiency of input water usage which can be maximized when the water input needs to be minimized (e.g. when water resources are scarce). Note that $\dot{n}_{\mathrm{H}_{2} \mathrm{O} .9}$ was determined by the reaction's thermodynamic equilibrium at state points 11 and 12 , which was not randomly chosen but requires the oxygen partial pressure at the outlet to match $p_{\mathrm{O}_{2}, 12}$.

The hydrogen productivity, $\chi_{\mathrm{H}_{2}}$, was the ratio between the production rate of hydrogen at $1 \mathrm{~kW}$ solar power input and the solid metal oxide rate required for the cycling,

$\chi_{\mathrm{H}_{2}}=\frac{\dot{n}_{\mathrm{H}_{2}, 12}}{\dot{n}_{\text {ceria }, 5}}$.

It quantified the efficiency of metal oxide utilization and indicated the amount of ceria which has to be moved in such a system.

All the aforementioned definitions are analogous when evaluating the $\mathrm{CO}_{2}$ dissociation for the $\mathrm{CO}$ production.

\section{Results}

\subsection{Operational feasibility for ceria-based fuel processing cycles}

The operational feasibility and limitation of the proposed ceria based thermochemical cycle schemes were given by two conditions: i) $\delta_{\text {red }}>\delta_{\text {ox }}$ to ensure a net fuel production, and $\left.i i\right)$ $p_{\mathrm{O}_{2}, 1} \leq p_{\mathrm{O}_{2}, 4} \leq p_{\text {system }}$ (not required for scheme (b)). The combinations of $T_{\text {red }}, \Delta T=T_{\text {red }}-T_{\mathrm{OX}}$, and $p_{\mathrm{O}_{2}, 4}$ for which condition $i$ ) is met are depicted in Fig. $2 \mathrm{a}$. The combinations for which condition ii) is met are depicted in Fig. 2 b.

For isothermal operation $\left(\Delta T=0\right.$ and $\left.p_{\mathrm{O}_{2}, 4}=p_{\mathrm{O}_{2}, 11}\right)$, condition ii) was fulfilled for all $T_{\text {red }}$ investigated $\left(1400<T_{\text {red }}<2100 \mathrm{~K}\right)$ at a 

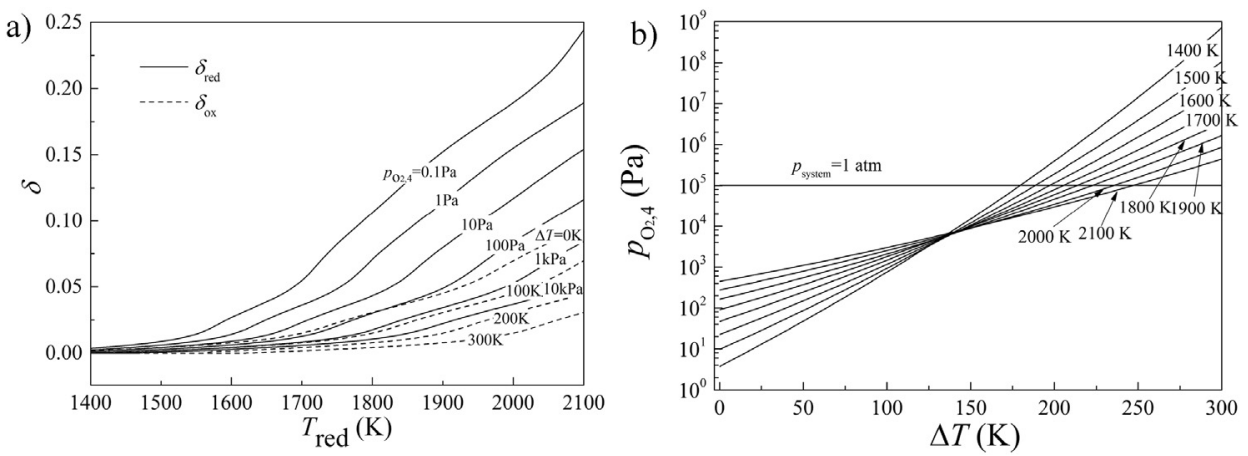

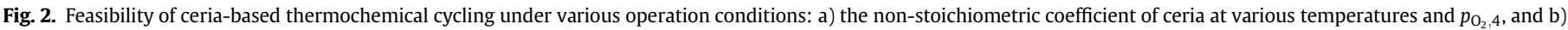
$p_{\mathrm{O}_{2}, 4}$ as a function of $\Delta T$ for various $T_{\text {red. }}$.

system pressures of $1 \mathrm{~atm}$. A system pressure as low as $6 \mathrm{mbar}$ could be tolerated. At $p_{\text {system }}=1 \mathrm{~atm}$, isothermal operation was feasible once the condition $\delta_{\text {red }}>\delta_{\text {ox }}$ is met, which required $p_{\mathrm{O}_{2}, 4}<100 \mathrm{~Pa}$ for $T_{\text {red }}>1800 \mathrm{~K}$ (see Fig. 2a). The higher $p_{\mathrm{O}_{2}, 4}$ the higher $T_{\text {red }}$ required for a positive net fuel production. The maximum $p_{\mathrm{O}_{2}, 1}$ that was possible for isothermal operation was about $460 \mathrm{~Pa}$ for $T_{\text {red }}>1400 \mathrm{~K}$. For non-isothermal operation $(\Delta T \neq 0)$, the largest possible $\Delta T$ was about $250 \mathrm{~K}$ for $p_{\text {system }}=1 \mathrm{~atm}$ and $T_{\text {red }}=2100 \mathrm{~K}$. The increase in $\Delta T$ from $0 \mathrm{~K}$ (isothermal) to $300 \mathrm{~K}$ enlarged the range of feasible operational conditions that still ensured $\delta_{\text {red }}>\delta_{\text {ox }}$ (see Fig. 2a), but also increased $p_{\mathrm{O}_{2}, 4}$, eventually requiring an increased system pressure for feasibility. An increase in $p_{\text {system }}$ increased the range of possible operational conditions, i.e. allows for larger $\Delta T$.

\subsection{Effects of temperature swing and oxygen partial pressure}

The $T_{\text {red }}, T_{\mathrm{ox}}$ (or $\Delta T$ ), $p_{\mathrm{O}_{2}, 1}$, and $p_{\text {system }}$ were the most significant operational parameters. Large $T_{\text {red }}$ led to increased heat losses (see eq. (5)), but increased $\delta_{\text {red, }}$, which increased the potential to produce hydrogen. Large $\Delta T$ resulted in increased hydrogen production due to the decreased $\delta_{\mathrm{ox}}$, while introducing an increased solid phase heat loss (see eq. (11)) if solid heat recovery was not practical or efficient. A smaller $p_{\mathrm{O}_{2}, 1}$ required higher flow rates of sweep gas and correspondingly more energy to heat up the sweep gas, or more pumping work for the vacuum pump. Nevertheless, small $p_{\mathrm{O}_{2}, 1}$ increased $\delta_{\text {red }}$ and provided a larger hydrogen production potential. A reference case was defined (see Table 1 ) for the subsequent optimization. Particularly, we optimized $\Delta T$ for maximum solar-to-fuel efficiency at a particular combination of $T_{\text {red }}$ and $p_{\mathrm{O}_{2}, 1}$.

Fig. 3 shows the calculated largest possible efficiencies for various combinations of $T_{\text {red }}$ and $p_{\mathrm{O}_{2}, 1}$, indicating the corresponding optimized $\Delta T$, for scheme (a) and (b). This efficiency is called optimal efficiency. Additionally, the efficiency for the same $T_{\text {red }}$ and $p_{\mathrm{O}_{2} \text {,red }}$ combinations at isothermal operation $(\Delta T=0)$ are shown. The corresponding energy distribution is depicted in Figs. 4 and 5 for scheme (a) and (b), respectively.

For scheme (a), the best performing cases for all combinations of $T_{\text {red }}$ and $p_{\mathrm{O}_{2}, 1}$ operated non-isothermally $(\Delta T>0)$. The optimal $\eta$ increased with increasing $T_{\text {red }}$ due to decreasing $\dot{Q}_{\text {gas }, 0 x}$, and increasing $\Delta \delta$, until $\dot{Q}_{\text {heat loss }}$ started to dominate the energy balance resulting in a decreasing $\eta$ (see Fig. 4d). The impact of $T_{\text {red }}$ on $\eta$ at isothermal operation is illustrated in Fig. $4 \mathrm{a}$ and revealed that initially $\dot{Q}_{\text {gas,red }}, \dot{Q}_{\text {gas }, o x}$, and $\dot{Q}_{\text {heat loss }}$ were dominating. The latter was continuously increasing with increasing $T_{\text {red, }}$, while the former two were monotonically decreasing at a faster rate.

Compared to the isothermal operation, a small $\Delta T$ led to a significantly higher $\eta$, i.e. the solar-to-fuel efficiency for $p_{\mathrm{O}_{2}, 1}=0.1 \mathrm{~Pa}, T_{\text {red }}=1800 \mathrm{~K}$ was $11 \%$ for isothermal operation and $31 \%$ at $\Delta T=135 \mathrm{~K}$. The increase of $\Delta T$, while increasing $\dot{Q}_{\text {solid }}$, resulted in a significant drop of $\delta_{\text {ox }}$ which results in an increase in the hydrogen production due to the increasing $\Delta \delta$ (see Fig. 4c). The amount of inert sweep gas required decreased with increasing $\Delta T$ due to significantly increasing $p_{\mathrm{O}_{2}, 4}$ and consequently reduced sweep gas amount hence reduced $\dot{Q}_{\text {gas,red }}$. At $\Delta T>150, \dot{Q}_{\text {cool,ox }}$ appeared and increased with $\Delta T$ reducing the efficiency gain brought by the decrease of $\dot{Q}_{\text {gas,red }}$ (Fig. 4c). This indicates that a temperature swing will largely increase the system performance compared to isothermal operation and there exist an optimal $\Delta T$ for the best performance which is in the rage of $125 \mathrm{~K}$.

Lowering $p_{\mathrm{O}_{2}, 1}$ always causes an increase in $\eta$ for a given $T_{\text {red }}$ due to the significant increase in $\delta_{\text {red }}$. The $T_{\text {red }}$ for optimal $\eta$ moved to higher values as $p_{\mathrm{O}_{2}, 1}$ increased while requiring larger $\Delta T$ (see Fig. 3a). For very large $p_{\mathrm{O}_{2}, 1}$, the low $\Delta \delta$ is the reason for low efficiencies. This can be alleviated by operating at larger $\Delta T$.

Table 1

Reference case parameters used for the comparison of the five different models of the ceria cycling.

\begin{tabular}{ll}
\hline Parameter & Value \\
\hline Direct normal irradiance, $I$ & 1 \\
Solar concentration ratio, $C$ & 3000 \\
System pressure, $p_{\text {system }}$ & 1 \\
Heat loss factor, $f$ & $0.2[31]$ \\
Heat-to-electricity efficiency, $\eta_{t}$ & 0.4 \\
Electricity-to-pumping efficiency, $\eta_{\text {pump }}{ }^{2}$ & $0.4[32]$ \\
Reduction temperature, $T_{\text {red }}$ & $1400-2100$ \\
Temperature swing, $\Delta T$ & $0-300$ \\
Oxygen partial pressure in the sweep gas for scheme $(\mathrm{a}), p_{\mathrm{O}_{2}, 1}$ & $1.1-20,000$ \\
Oxygen absolute pressure in the reduction chamber for scheme $(\mathrm{b}), p_{\mathrm{O}_{2}, 1}$ & $1.1-20,000$ \\
Ambient temperature, $T_{0}$ & 298 \\
Heat recovery effectiveness for gases, $\varepsilon_{\mathrm{g}}$ & $\mathrm{K}$ \\
Heat recovery effectiveness for solid, $\varepsilon_{S}$ & $\mathrm{~K}$ \\
\hline
\end{tabular}



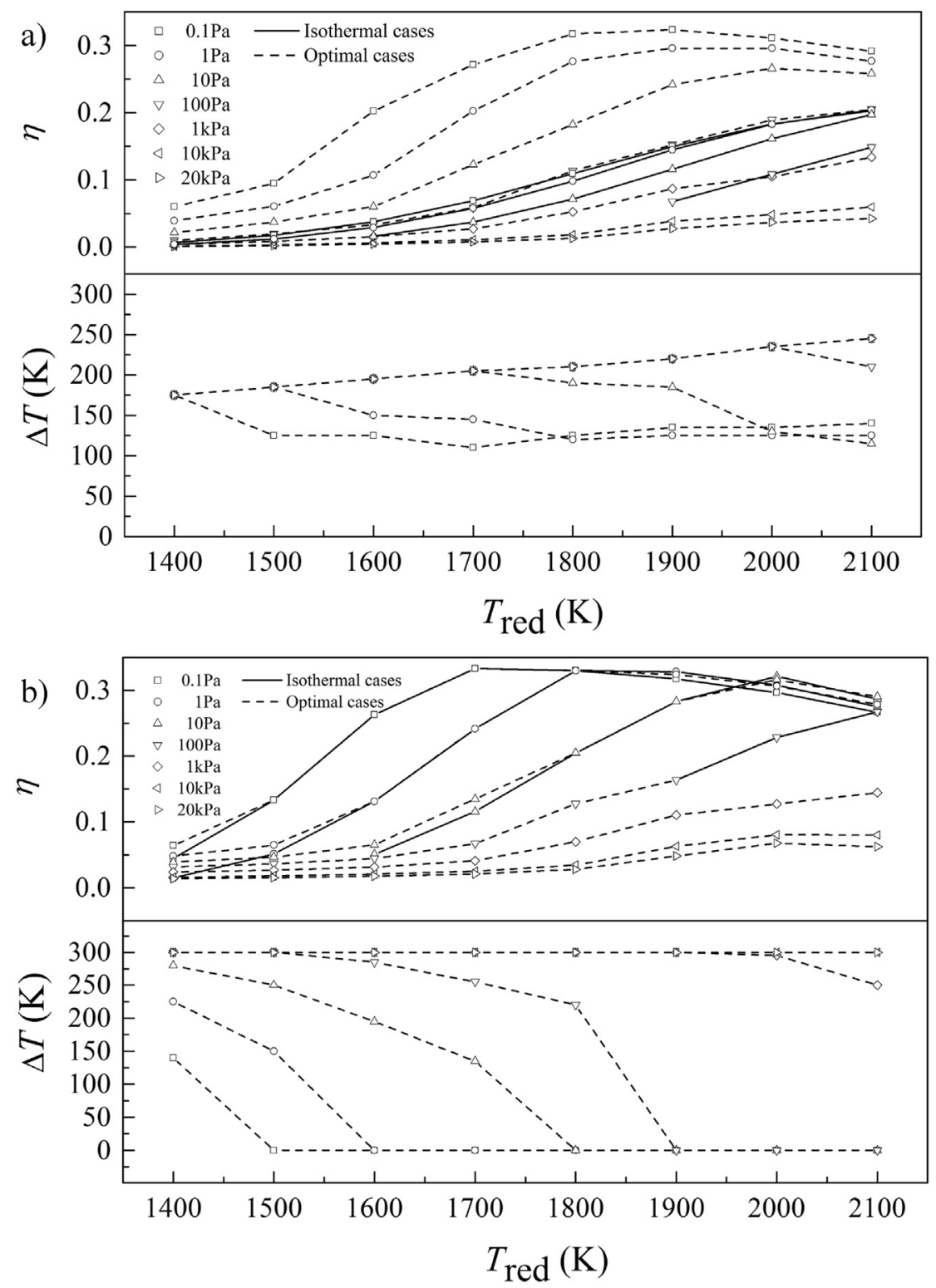

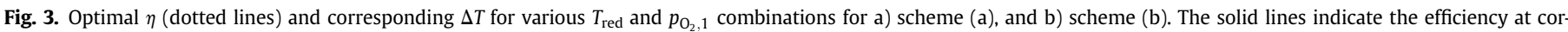
responding $T_{\text {red }}$ and $p_{\mathrm{O}_{2}, 1}$ for isothermal operation $(\Delta T=0)$.

Small $\delta_{\text {red }}$ resulted at low $T_{\text {red }}$ and large $p_{\mathrm{O}_{2}, 1}$. These combinations required a large $\Delta T$ (often unfeasible, see Fig. $2 \mathrm{~b}$ ) for reasonable efficiencies and comparatively higher $\Delta \delta$. As $T_{\text {red }}$ increased, $\delta_{\text {red }}$ increased gradually leading to a dominating $\dot{Q}_{\text {ceria }}$ and corresponding required a decrease in $\Delta T$, for optimal $\eta$ (see Fig. 3a). For $p_{\mathrm{O}_{2}, 1}>100 \mathrm{~Pa}, \Delta T$ was always restricted by the feasibility conditions and consequently the activity of the reduction of ceria is hindered at large $p_{\mathrm{O}_{2}, 1}$. A slight increase in $\Delta T$ was detected for $p_{\mathrm{O}_{2}, 1}=0.1 \mathrm{~Pa}$ and $1 \mathrm{~Pa}$ at $1700 \mathrm{~K}$ and $1800 \mathrm{~K}$, respectively. This is due to the appearance of $\dot{Q}_{\text {cool,ox }}$ at high temperatures which can partly be compensated by a larger $\Delta T$.

The results for scheme (b) revealed that the optimal $\eta$ under various given $T_{\text {red }}$ and $p_{\mathrm{O}_{2}, 1}$ tend to work at lower $\Delta T$ which favored isothermal operation compared to scheme (a). This trend was especially pronounced at higher temperatures ( $T_{\text {red }} \geq 1800 \mathrm{~K}$ ). This was caused by the increase in $\Delta \delta$ and decrease in $\dot{Q}_{\text {pump }}$ and $\dot{Q}_{\text {gas }, 0 x}$ with increasing $\Delta T$ and $T_{\text {red, }}$ which was overcompensated by the increasing $\dot{Q}_{\text {cool,ox }}$ and $\dot{Q}_{\text {ceria }}$ (see Fig. 5c and dc).

Similar trends in the optimal $\eta$ (i.e. at non-isothermal conditions, $\Delta T \neq 0$ ) were observed for scheme (b) and scheme (a). Increasing $p_{\mathrm{O}_{2}, 1}$ led to a significant reduction in $\eta$ for the whole range of $p_{\mathrm{O}_{2}, 1}$ studied $(0.1 \mathrm{~Pa}-20000 \mathrm{~Pa})$ for $T_{\text {red }}<1700 \mathrm{~K}$. For $T_{\text {red }}>1700$, $p_{\mathrm{O}_{2}, 1}>0.1 \mathrm{~Pa}$ showed larger optimal $\eta$ than $p_{\mathrm{O}_{2}, 1}=0.1 \mathrm{~Pa}(\eta=30 \%$ for $p_{\mathrm{O}_{2}, 1}=0.1 \mathrm{~Pa}$, and $\eta=31 \%$ for $p_{\mathrm{O}_{2}, 1}=1 \mathrm{~Pa}$ at $T_{\text {red }}=2000 \mathrm{~K}$ ) due to the decrease in $\dot{Q}_{\text {pump }}, \dot{Q}_{\text {cool,ox }}$, and $\dot{Q}_{\text {cool,red }}$ at high $T_{\text {red }}$ (Fig. $5 \mathrm{~b}$ and $5 d$ ) which overruled the decrease of $\Delta \delta$.

The efficiencies of the system for $\mathrm{CO}_{2}$ splitting (eqs. (1) and (3)) showed similar trends as the ones described for water splitting in schemes (a) and (b) with generally higher efficiencies due to larger equilibrium constants for the oxidation reaction in the $\mathrm{CO}_{2}$ splitting system. The efficiency variations for solar thermochemical ceriabased $\mathrm{CO}_{2}$ splitting for varying $T_{\mathrm{red}}, p_{\mathrm{O}_{2}, 1}$, and $\Delta T$ are shown in Figs. S1 and S2. 
a)

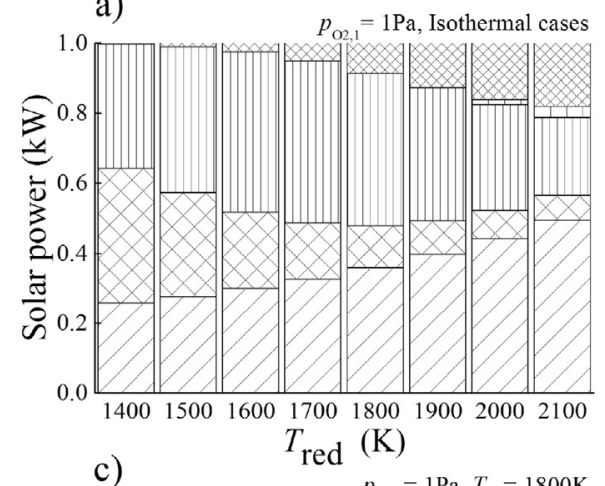

c)

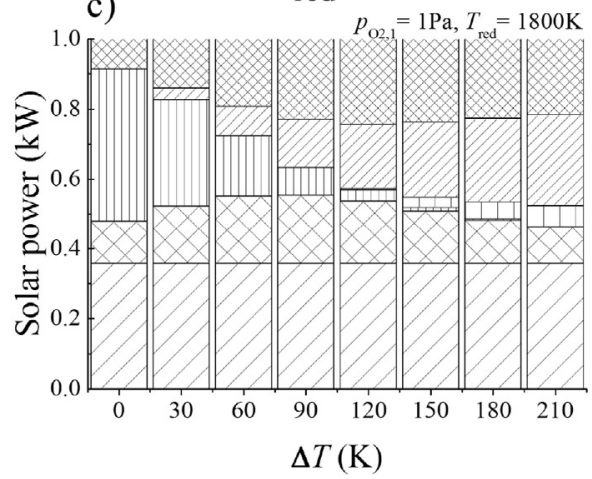

b)

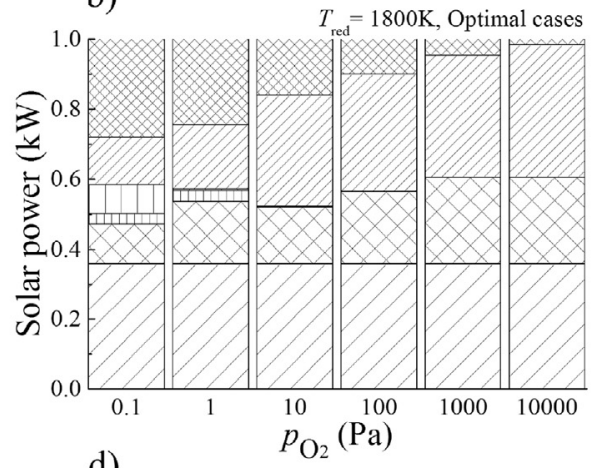

d)

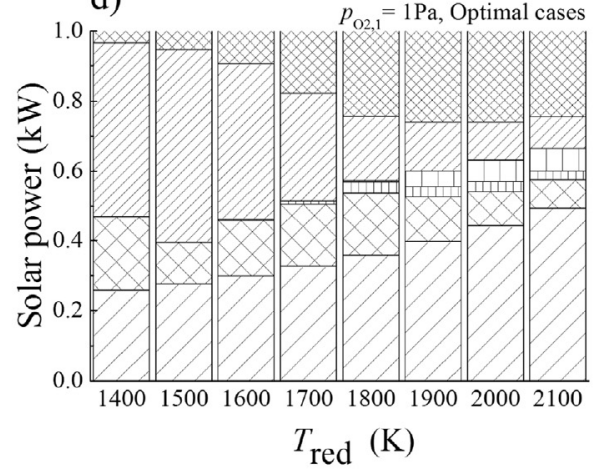

$Q_{\text {react }} \square \Delta Q_{\text {ceria }} \square Q_{\text {cool,ox }} \amalg Q_{\text {gas,red }} \otimes Q_{\text {gas,ox }} \square Q_{\text {heat loss }}$

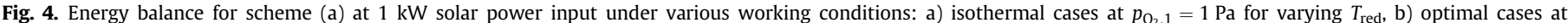
$T_{\text {red }}=1800 \mathrm{~K}$ for varying $p_{\mathrm{O}_{2}, 1}$, c) cases at $p_{\mathrm{O}_{2}, 1}=1 \mathrm{~Pa}$ and $T_{\text {red }}=1800 \mathrm{~K}$ for varying $\Delta T$, and d) optimal cases at $p_{\mathrm{O}_{2}, 1}=1$ Pa for varying $T_{\text {red. }}$
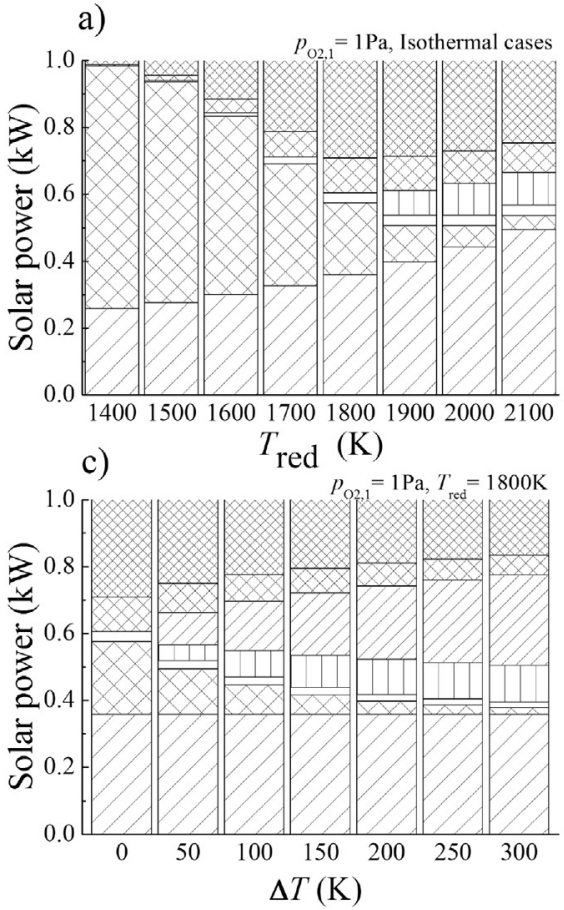

$Q_{\text {react }} Q_{\text {pump }} \amalg Q_{\text {ceria }}$ b)
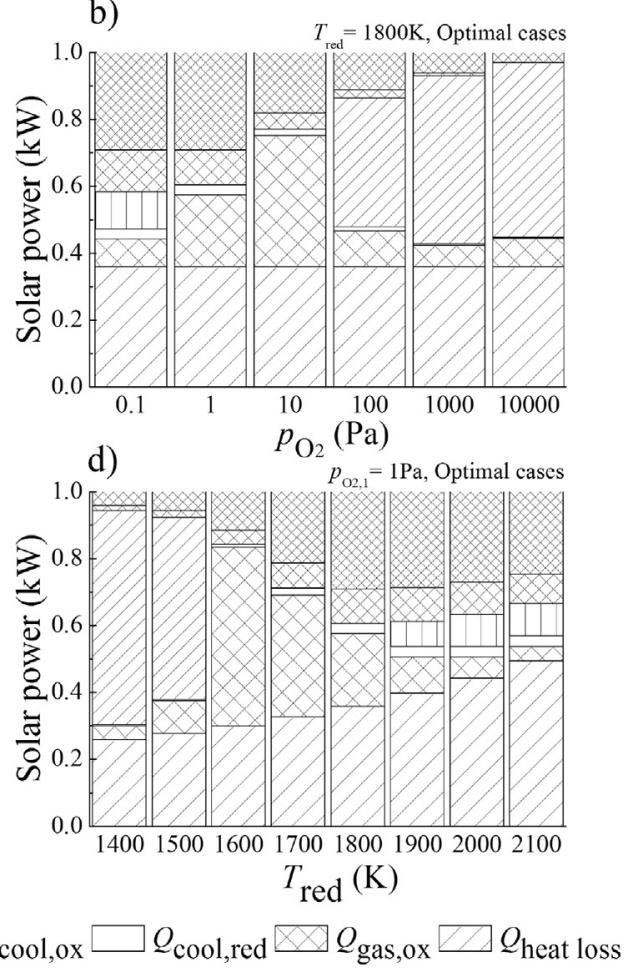

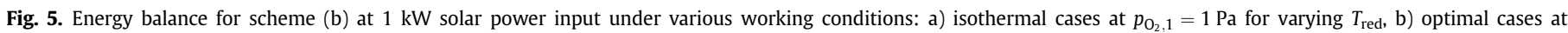
$T_{\text {red }}=1800 \mathrm{~K}$ for varying $p_{\mathrm{O}_{2}, 1}, \mathrm{c}$ ) cases at $p_{\mathrm{O}_{2}, 1}=1 \mathrm{~Pa}$ and $T_{\text {red }}=1800 \mathrm{~K}$ for varying $\Delta T$, and d) optimal cases at $p_{\mathrm{O}_{2}, 1}=1$ Pa for varying $T_{\text {red }}$ 


\subsection{Hydrogen productivity}

In addition to an optimized solar-to-fuel efficiency, the hydrogen productivity should be maximized in order to minimize the amount of metal oxide which needs to be cycled (pumping requirements), bought and refilled (economic investment), and mined and recycled (sustainability issue).

$\chi_{\mathrm{H}_{2}}$ is shown in Fig. 6 exemplary for a practical $T_{\text {red }}$ of $1800 \mathrm{~K} \chi_{\mathrm{H}_{2}}$ increased with increasing $\Delta T$ and decreasing $p_{\mathrm{O}_{2}, 1}$. The two zones shown in Fig. 6 distinguished the accessibility of $\Delta T$ for scheme (a) and scheme (b) as discussed in section 3.1. For scheme (a), the $\Delta T$ was limited by $p_{\mathrm{O}_{2}, 4}$ and the operation is only possible in zone 1 . For scheme (b), the operation was not confined by $p_{\mathrm{O}_{2}, 4}$ and hence zone 1 and zone 2 were accessible. The increase in $\Delta T$ effected a lower $\delta_{\text {ox }}$ resulting in a larger $\Delta \delta$ and correspondingly larger $\chi_{\mathrm{H}_{2}}$. Generally, the optimal efficiencies of scheme (a) were situated at $\Delta T>0$ and correspondingly higher hydrogen productivities were achieved (indicated by the hollow dots in Fig. 6) compared to the optimal efficiencies of scheme (b), which usually were isothermal or at low $\Delta T$ (for $p_{\mathrm{O}_{2}, 1}<100 \mathrm{~Pa}$ ). For $p_{\mathrm{O}_{2}, 1} \geq 100 \mathrm{~Pa}$, large $\chi_{\mathrm{H}_{2}}$ were achieved in scheme (b), however, $\eta$ was significantly limited by low $\Delta \delta$. Generally, operating at optimal efficiencies and low $p_{\mathrm{O}_{2}, 1}$ required more ceria per produced hydrogen for vacuum pumping approach (scheme (b)) compared to sweep gassing (scheme (a)). Since the sensitivity of the efficiency with the variation of $\Delta T$ for scheme (b) at $1800 \mathrm{~K}$ is small (see Fig. $5 \mathrm{c}$ ), it is possible to optimize the operational conditions for scheme (b) by operating at a small $\Delta T$ (within $150 \mathrm{~K})$ to achieve both high solar-to-fuel efficiency $(28 \%$ at $T_{\text {red }}=1800 \mathrm{~K}, p_{\mathrm{O}_{2}, 1}=1 \mathrm{~Pa}$, and $\Delta T=120 \mathrm{~K}$ ) and comparatively larger hydrogen productivity.

\subsection{Water utilization factor}

Fig. 7 exemplary shows $f_{\mathrm{w}}$ for schemes (a) and (b) at $T_{\text {red }}=1800 \mathrm{~K}$ for varying $p_{\mathrm{O}_{2}, 1}$ and $\Delta T$. Generally, lower $p_{\mathrm{O}_{2}, 1}$ and higher $\Delta T$ led to larger $f_{\mathrm{w}}$. $\delta_{\text {red }}$ increases and correspondingly $p_{\mathrm{O}_{2}, 12}$ decreased with decreasing $p_{\mathrm{O}_{2}, 1}$ hence requiring a smaller water input. The enhancement in $f_{\mathrm{w}}$ with increasing $\Delta T$ was more pronounced at lower $p_{\mathrm{O}_{2}, 1}$ in accordance with a larger $\Delta \delta$ at these conditions and more efficient water use. The increase in $f_{\mathrm{w}}$ with increasing $\Delta T$ resulted from the lower $p_{\mathrm{O}_{2}, 1}$ at higher $\Delta T$.

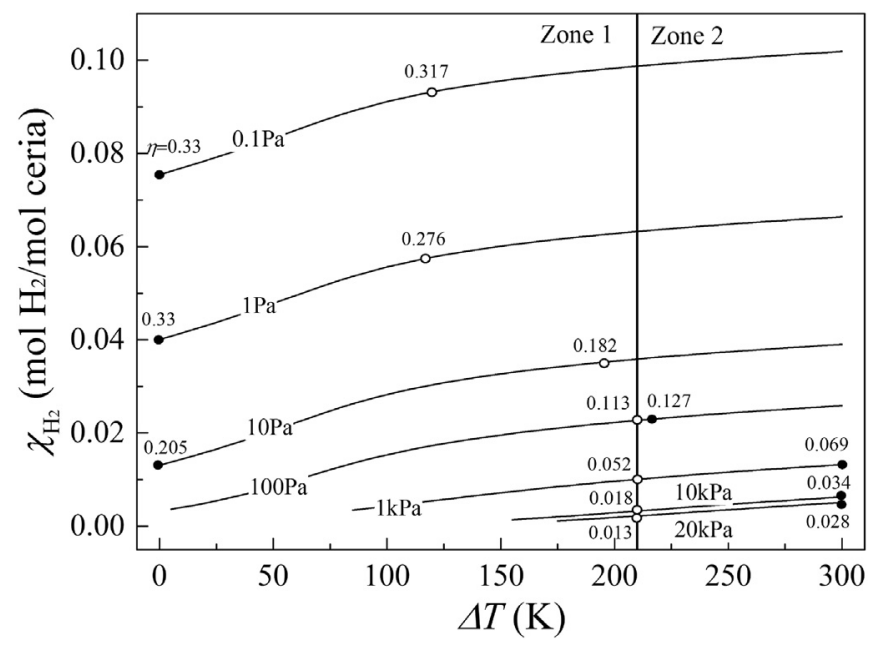

Fig. 6. $\mathrm{H}_{2}$ productivity as a function of $\Delta T$ for different $p_{\mathrm{O}_{2}, 1}$ at $T_{\text {red }}=1800 \mathrm{~K}$ for scheme (a) (Zone 1) and scheme (b) (Zones 1 and 2). Dots indicate the optimal efficiency at the corresponding conditions ( $\Delta T$ and $p_{\mathrm{O}_{2}, 1}$ ) for scheme (a) (hollow dots) and scheme (b) (filled dots).

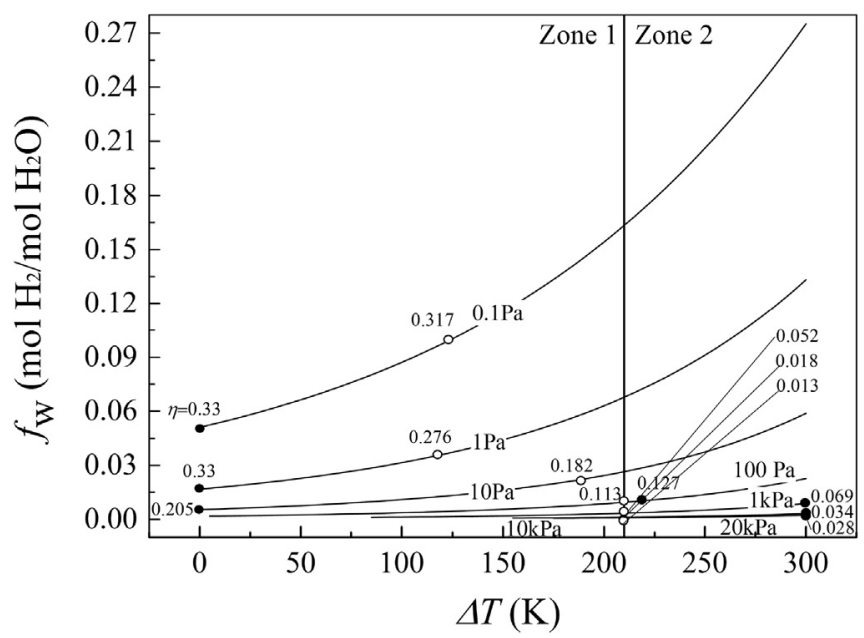

Fig. 7. $f_{\mathrm{w}}$ as a function of $\Delta T$ for different $p_{\mathrm{O}_{2}, 1}$ at $T_{\text {red }}=1800 \mathrm{~K}$ for scheme (a) (Zone 1 ) and scheme (b) (Zones 1 and 2). Dots indicate the optimal efficiency at the corresponding conditions ( $\Delta T$ and $p_{\mathrm{O}_{2}, 1}$ ) for scheme (a) (hollow dots) and scheme (b) (filled dots).

Similar as for $\chi_{\mathrm{H}_{2}}$, scheme (a) worked at higher efficiency when $\Delta T \neq 0$, which in turn resulted in larger $f_{\mathrm{w}}$. For scheme (b), isothermal operation led to higher $\eta$ while unfavorably reduced the hydrogen productivity and $f_{\mathrm{w}}$, which increased the consumption of input materials (water and ceria).

\subsection{Pump efficiency}

The electricity-to-pump efficiency, $\eta_{\text {pump }}$, for scheme (b) was assumed constant (40\%) but practical vacuum pumps (rotary vane, piston, scroll, or roots pumps) show non-constant efficiencies changing with working conditions (pressure and flow rate). The effect of the decreasing pump efficiency with decreasing $p_{\mathrm{O}_{2}, 1}$ is depicted in Fig. 8a for a turbo molecular vacuum pump system of Pfeiffer Vacuum with a pump efficiency estimated as [32],

$\eta_{\text {pump }}=0.4+0.07 \log \frac{p_{\mathrm{O}_{2}, 1}}{p_{0}}$.

The optimal $\eta$ was significant affected by $\eta_{\text {pump }}$ at low $p_{\mathrm{O}_{2}, 1}$ due to the decrease in $\eta_{\text {pump }}$ with decreasing $p_{\mathrm{O}_{2}, 1}$. The increased power required for reducing the oxygen partial pressure is offset through an increase in $T_{\text {red. }}$.

The optimal $\eta$ was achieved at isothermal operation at low $p_{\mathrm{O}_{2}, 1}$, supporting the previous conclusion that vacuum pumping is the method of choice to lower the $p_{\mathrm{O}_{2}, 1}$ at isothermal conditions. The effect of $\eta_{\text {pump }}$ on the optimal $\eta$ under different $p_{\mathrm{O}_{2}, 1}$ is depicted in Fig. $8 \mathrm{~b}$ and exhibits that $\eta_{\text {pump }}$ of $40 \%$ is required to overcome the limitations posed by the pumping work. Further increase in $\eta_{\text {pump }}$ showed no significant increase in the solar-to-fuel efficiency. These investigations provide guidelines for the choice of the vacuum pump technology and quality.

\subsection{Heat recovery effectiveness}

\subsubsection{Gas phase heat recovery effectiveness}

Gas phase heat recovery is crucial in dictating a large $\eta$ [13]. As depicted in Fig. 9a, the larger $\varepsilon_{\mathrm{g}}$ the larger $\eta$ at isothermal condition for scheme (a). $\varepsilon_{\mathrm{g}}$ as high as 0.975 was required for $\eta>10 \%$ at $T_{\text {red }}=1700 \mathrm{~K}$. The increase in $\eta$ was more pronounced at larger $\varepsilon_{\mathrm{g}}$ and with increasing $T_{\text {red, }}$, further suggesting that the requirements on the high temperature heat exchanger manufacturing and maintenance were stringent when considering isothermal 

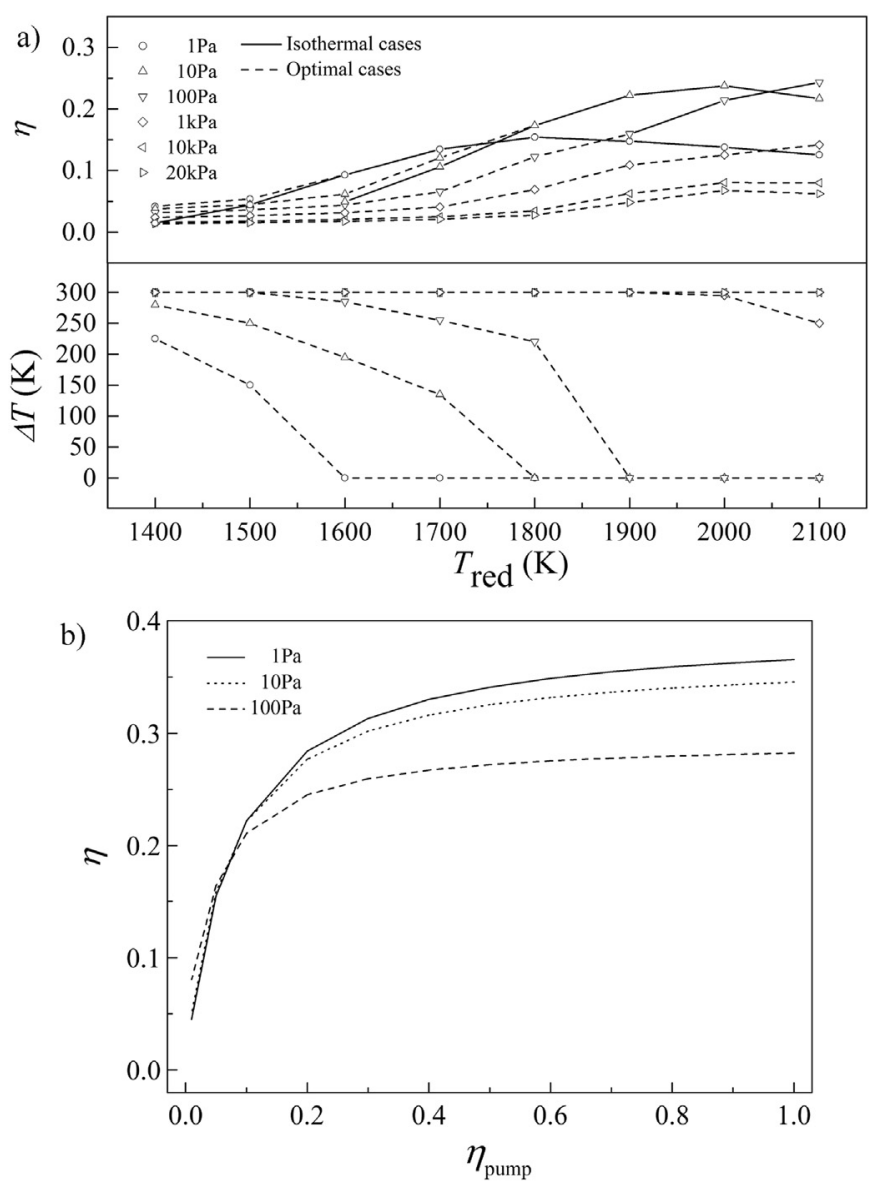

Fig. 8. a) Optimal $\eta$ for various $T_{\text {red }}$ and $p_{\mathrm{O}_{2}, 1}$ for scheme (b) with changing $\eta_{\text {pump }}$ according to eq. (18), and b) optimal $\eta$ as a function of $\eta_{\text {pump }}$ for three different $p_{\mathrm{O}_{2}, 1}$ (1 $\mathrm{Pa}, 10 \mathrm{~Pa}$, and $100 \mathrm{~Pa}$ ). operation. The requirements on the heat exchanger can be relaxed through the use of a temperature swing as depicted in Fig. 9b. At $\varepsilon_{\mathrm{g}}<0.9$, the maximum $\eta$ appeared at the largest possible $\Delta T$, where $\Delta T$ was limited by the operational feasibility (see section 3.1). For $\varepsilon_{\mathrm{g}}>0.9$, the highest solar-to-fuel efficiency was observed at an optimized $\Delta T$ which maximized the $\Delta \delta$ while limiting $\dot{Q}_{\text {ceria. }}$.

For scheme (b), increasing $\varepsilon$ g at isothermal operation led to a significant increase in $\eta$ at lower $T_{\text {red }}\left(T_{\text {red }}<1800 \mathrm{~K}\right)$, while a less pronounced effect was exhibited at high $T_{\text {red }}$ (see Fig. 9c) due to the exhibited dominance of $\dot{Q}_{\text {heat loss }}$ (see Fig. 5). Compared to scheme (a), the requirements on the heat exchanger were less stringent and already a $\varepsilon_{\mathrm{g}}$ of 0.85 was sufficient to reach $\eta>10 \%$ at $T_{\text {red }}=1700 \mathrm{~K}$. The requirements on the heat exchanger can be further relaxed when operating non-isothermally, as depicted in Fig. 9d. At $\Delta T=300 \mathrm{~K}, \eta$ was equal for $\varepsilon_{\mathrm{g}}=0.5$ and 0.975 . An optimal $\Delta T$ for maximized optimal efficiency was observed for $\varepsilon_{\mathrm{g}}<0.9$. This resulted from a tradeoff between decreasing $\dot{Q}_{\text {gas }, 0 x}$ and increasing $\dot{Q}_{\text {ceria }}$ and $\dot{Q}_{\text {cool,ox }}$ as $\Delta T$ increased. For $\varepsilon_{\mathrm{g}}>0.9$, the decrease in $\dot{Q}_{\text {gas }, 0 x}$ with increasing $\Delta T$ was not observable as $\dot{Q}_{\text {ceria }}$ and $\dot{Q}_{\text {cool,ox }}$ dominated the losses already at $\Delta T=0$ and further increased with increasing $\Delta T$. Consequently, for $\varepsilon_{\mathrm{g}}>0.9$, isothermal operation resulted in the best performing solar-to-fuel efficiency. This feature of scheme (b) indicates that $\varepsilon_{\mathrm{g}} \geq 0.9$ is required to ensure that isothermal operation results in the highest solar-to-fuel efficiency for a certain $T_{\text {red }}$ and $p_{\mathrm{O}_{2}, 1}$ combination. Nevertheless, the introduction of a small $\Delta T$ can significantly reduce the requirements on the heat exchanger at a reasonable penalty in solar-to-fuel efficiency, i.e. introducing a $\Delta T$ of $50 \mathrm{~K}$ reduced the solar-to-fuel efficiency by $5.2 \%$ at $\varepsilon_{\mathrm{g}}=0.975$.

For $\varepsilon_{\mathrm{g}}=1$, the solar-to-fuel efficiency solely decreased with increasing $T_{\text {red }}$ for isothermal operation of schemes (a) and (b), e.g. the efficiency of scheme (a) decreased from $50.8 \%$ to $36.4 \%$ as $T_{\text {red }}$ increased from $1400 \mathrm{~K}$ to $2100 \mathrm{~K}$. This was explained by the fact that the usually dominating $\dot{Q}_{\text {gas,red }}$ and $\dot{Q}_{\text {gas.ox }}$ (see Fig. 4a and 5a) were significantly reduced and the energy balance was then dominated by the monotonically increasing $\dot{Q}_{\text {heat loss. }}$ The solar-to-fuel
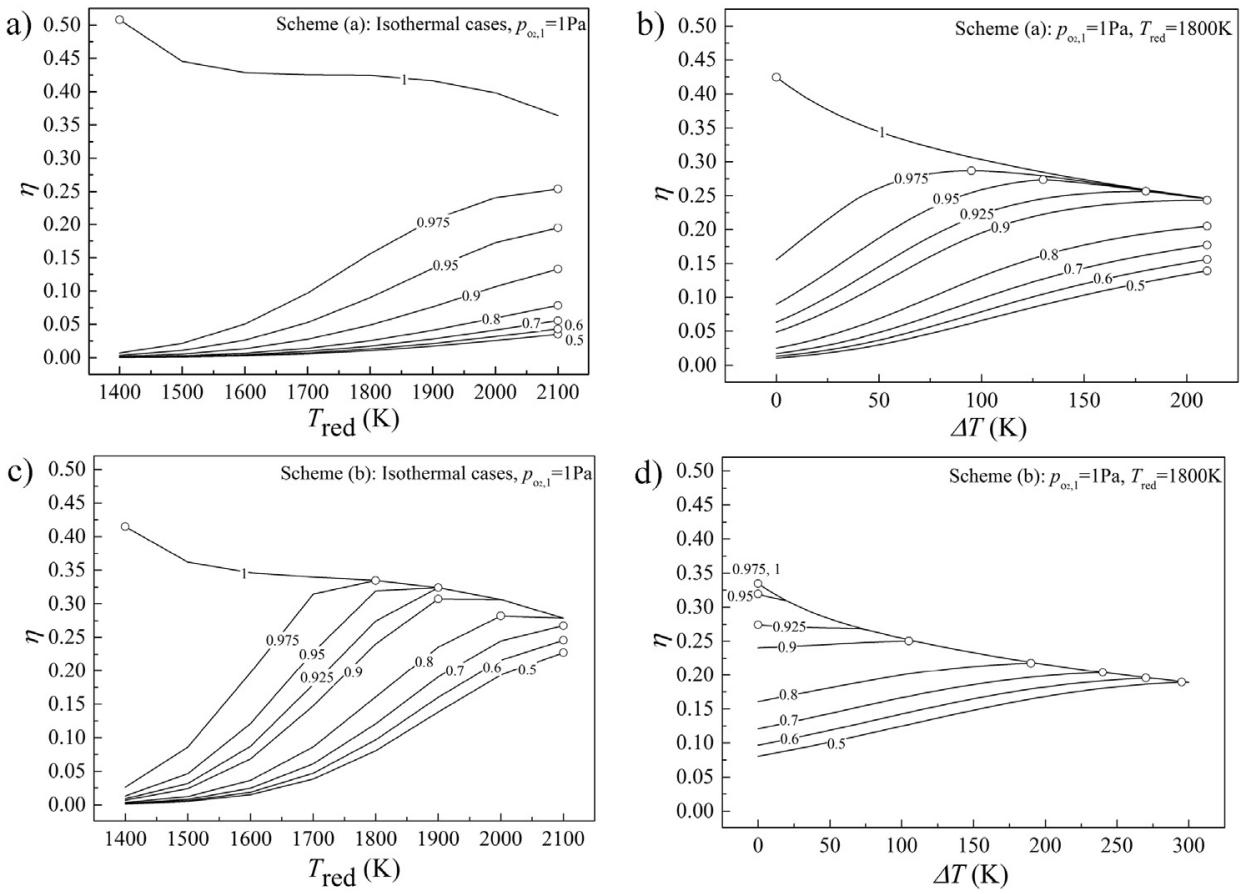

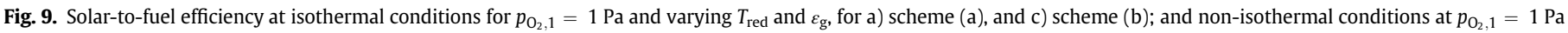
and $T_{\text {red }}=1800 \mathrm{~K}$ for varying $\Delta T$ and $\varepsilon_{\mathrm{g}}$, for b) scheme (a), and d) scheme (b). The maximal efficiencies for each $\varepsilon_{\mathrm{g}}$ are marked by the dots. 

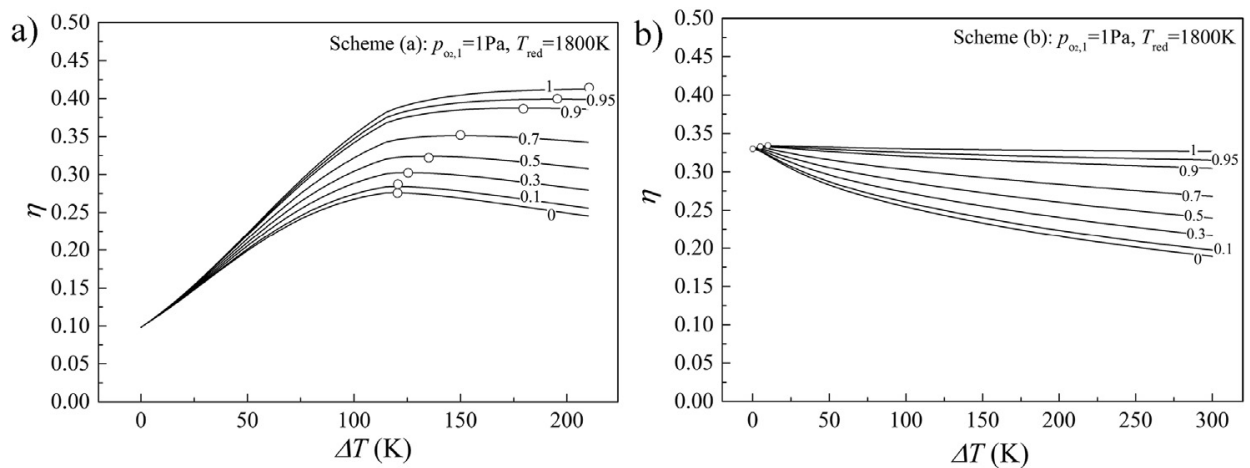

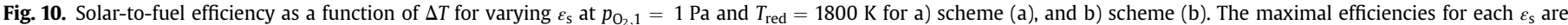
marked by the dots.

efficiency was significantly increased at perfect gas heat recovery: the solar-to-fuel efficiency increased up to $50 \%$ at $T_{\text {red }}=1400 \mathrm{~K}$ when $\varepsilon_{\mathrm{g}}$ increases from 0.975 to 1 for scheme (a). Similar behavior was observed for the non-isothermal operation of scheme (a) at $\varepsilon_{\mathrm{g}}=1$, namely solely a decrease in solar-to-fuel efficiency with increasing $\Delta T$, which could again be explained by the reduction of the otherwise dominating $\dot{Q}_{\text {gas,red }}$ and $\dot{Q}_{\text {gas,ox }}$.

\subsubsection{Solid phase heat recovery effectiveness}

Effects of $\varepsilon_{\mathrm{S}}$ on $\eta$ for varying $\Delta T$ are depicted in Fig. 10 at $T_{\text {red }}=1800 \mathrm{~K}$ and $p_{\mathrm{O}_{2} \text {,red }}=1 \mathrm{~Pa}$. Generally, $\eta$ increased with increasing $\varepsilon_{s}$. This enhancement was more pronounced for larger $\Delta T$ due to the increased recuperation of $\dot{Q}_{\text {solid }}$. For scheme (a), a significant raise in the maximal optimal $\eta$ of absolute $5 \%$ was observed when raising $\varepsilon_{S}$ from 0 to 0.5 . The optimal $\Delta T$ increased for maximal optimal $\eta$ with increasing $\varepsilon_{\mathrm{s}}$ due to reduction in $\dot{Q}_{\text {solid }}$. $\dot{Q}_{\text {solid }}$ became less significant when $\varepsilon_{s}$ increased above 0.5 and therefore the benefit of an increasing $\Delta \delta$ at higher $\Delta T$ dominated over the increased $\dot{Q}_{\text {solid }}$ and $\dot{Q}_{\text {cool,ox }}$.
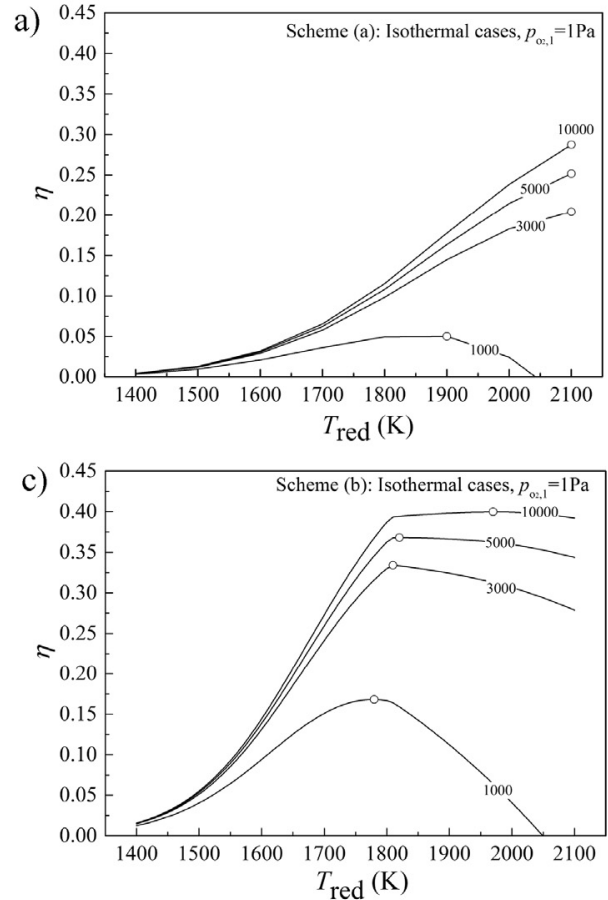

As shown in Fig. 10b, scheme (b) displayed the maximal $\eta$ at isothermal operation. $\eta$ decreased with increasing $\Delta T$ at $\varepsilon_{\mathrm{S}}<0.9$ due to increase in $\dot{Q}_{\text {solid }}$ and $\dot{Q}_{\text {coolox }}$, which counteracted the decrease in $\dot{Q}_{\text {pump }}$ and increase in $\Delta \delta$. At $\varepsilon_{\mathrm{s}} \geq 0.9$, a small $\Delta T$ of about $10 \mathrm{~K}$ led to increased $\eta$ due to the increase of $\Delta \delta$ while the increase in $\dot{Q}_{\text {cool.ox }}$ and $\dot{Q}_{\text {solid }}$ were insignificant. As $\Delta T$ increased further, the benefit of increased $\Delta \delta$ became insignificant compared to the increasing losses.

\subsection{Concentration ratio}

The impact of concentration ratio, $C$, on $\eta$ for schemes (a) and (b) is shown in Fig. 11. The $C$ of a solar concentration system was determined by the type of the concentrator used and chosen from 1000 to 10,000 according to the feasibility of solar tower and dish systems [9].

Generally, higher $C$ led to higher $\eta$, although the increase in $\eta$ became small for $C>5000$. For isothermal operation, $\eta$ increased with $T_{\text {red }}$ due to increasing $\Delta \delta$ and decreased due to the dominance

b)

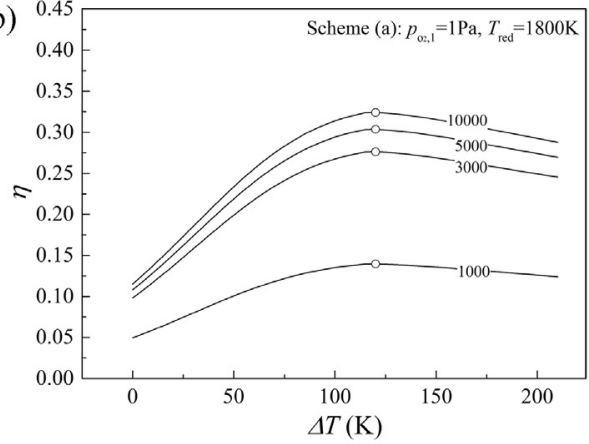

d)

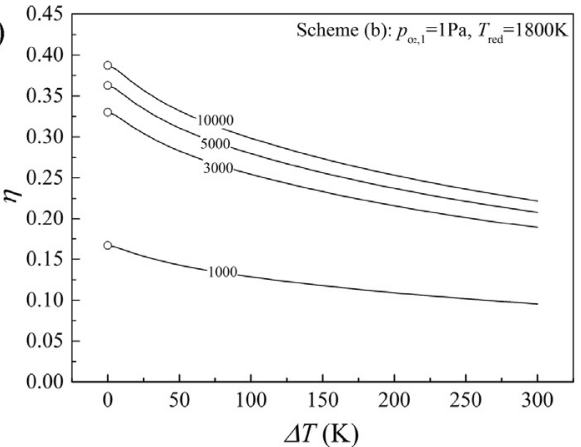

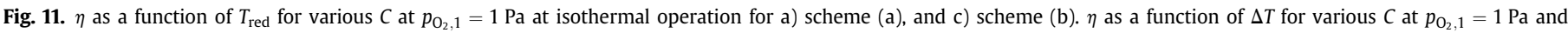
$T_{\text {red }}=1800 \mathrm{~K}$ for b) scheme (a), and d) scheme (b). The maximal efficiencies for each $C$ are marked by the dots. 
of $\dot{Q}_{\text {heat loss }}$ at high $T_{\text {red. }}$ The decrease in $\eta$ was reduced at increased $C$ as the aperture was reduced and correspondingly the losses were relatively reduced (see eq. (5)). The optimal $T_{\text {red }}$ for maximal $\eta$ increased for the isothermal cases in schemes (a) and (b) due to the beneficial higher $\Delta \delta$. For the selected cases at $T_{\text {red }}=1800 \mathrm{~K}$, the optimal $\Delta T$ for maximal optimal $\eta$ was always at $120 \mathrm{~K}$ for scheme (a) and $0 \mathrm{~K}$ for scheme (b), respectively.

\subsection{Reduction in the oxygen partial pressure through combined mechanical and mechanical-chemical approaches}

Reduction in $p_{\mathrm{O}_{2}, 1}$ had the potential to significantly increase the solar-to-fuel efficiency. In order to further decrease the oxygen partial pressure while circumventing low pumping efficiencies, high pumping power requirements, or significant sensible heat losses required to heat the inert gas, a combination of mechanical and chemical techniques to reduce the oxygen partial pressure were proposed. Specifically, scheme (a) in combination with a chemical oxygen scavenger made of magnesium (scheme (c)) was investigated. The magnesium acted as reducing agent and reacts with the oxygen before it enters the reduction chamber. Magnesium is a strong reducing agent and is able to reduce the $p_{\mathrm{O}_{2}}$ in sweep gas to values lower than $10^{-17}$ atm [33]. The calculated efficiencies of scheme (c) under different $p_{\mathrm{O}_{2}, 1}$ are shown in Fig. 12a. The energy penalty introduced for $\mathrm{MgO}$ recycling was $3600 \mathrm{~kJ} / \mathrm{mol}$ assuming $\mathrm{MgO}$ reduction by the Bolzano process [31]. The chemical reduction of $p_{\mathrm{O}_{2}, 1^{\prime}}$ in the sweep gas led to higher $\eta$ for the optimal cases because of a further reduction in the required sweep gas. For isothermal operation, the use of an oxygen scavenger showed no increase in $\eta$ as the energy penalty caused by the large amount of magnesium required to scavenger the oxygen of the large amount of sweep gas traded off the increase in efficiency due by lower $p_{\mathrm{O}_{2}, 1}$.

The effect of $\dot{Q}_{\mathrm{Mg}, \mathrm{pr}}$ on the solar-to-fuel efficiency of the system is depicted in Fig. 12b and showed no significant efficiency penalty for the selected values of $\dot{Q}_{\mathrm{Mg} \text {,pr }}$ between 0 and $9000 \mathrm{~kJ} / \mathrm{mol}$, which corresponded to free $\mathrm{MgO}$ recycling and $\mathrm{MgO}$ recycling by the Pidgeon process [31].

A combination of sweep gassing, vacuum pumping, and chemical scavenger (scheme e) allowed for a further increase in efficiency due to a decrease in system pressure. The basic idea of this combination was to reduce $p_{\mathrm{O}_{2}, 1}$ in the sweep gas from the baseline value ( $1 \mathrm{~Pa})$, to a target value $(0.1 \mathrm{~Pa})$ through the oxygen scavenger. The vacuum pump was then used to further reduce the $p_{\mathrm{O}_{2}, 1}$ in reduction chamber by reducing the system pressure, $p_{\text {system. }}$. Fig. 13 depicts the change of $\eta$ with different $p_{\text {system }}$ for both optimal and isothermal operations when varying $p_{\text {system }}$ between $1 \mathrm{~atm}$ and $0.1 \mathrm{~atm}$. For isothermal operation, we observed a minimum in $\eta$ when decreasing $p_{\text {system }}$ from $1 \mathrm{~atm}$ to $0.1 \mathrm{~atm}$. The maximal $\eta$ was

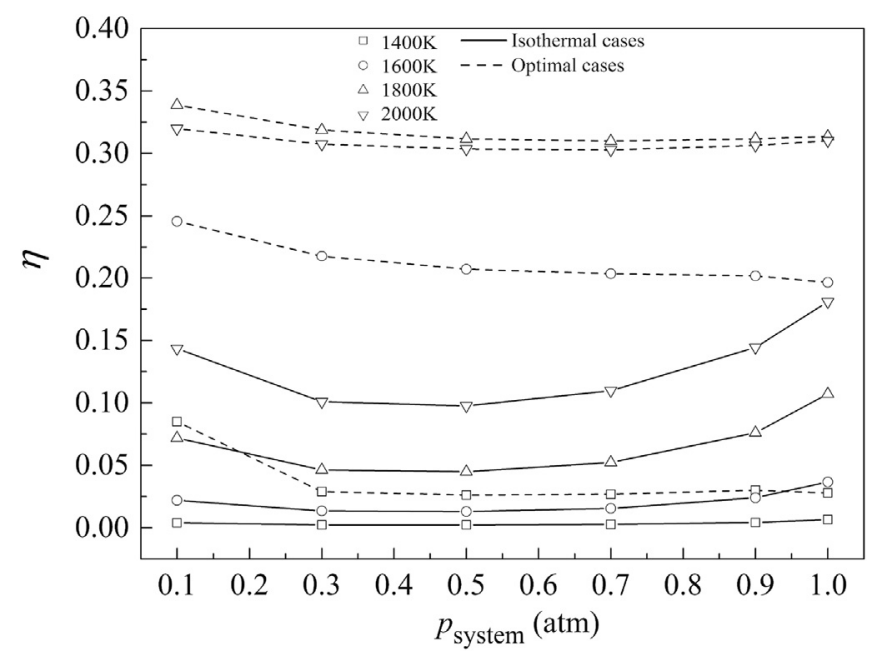

Fig. 13. $\eta$ as a function of $p_{\text {system }}$ for various $T_{\text {red }}$ at $\dot{Q}_{\mathrm{Mg} . \mathrm{pr}}=3600 \mathrm{~kJ} / \mathrm{mol}$ for both optimal and isothermal cases for scheme (c).

observed at $p_{\text {system }}=1 \mathrm{~atm}$ as the gain in efficiency with decreasing $\delta_{\text {red }}$ at low oxygen partial pressure was overruled by the large pumping work due to the large amount of sweep gas needed in isothermal operation.

For the optimal cases, a reduction in $p_{\text {system }}$ increased the efficiency. This effect was less pronounced at higher temperatures as the amount of sweep gas required was higher at higher $T_{\text {red }}$ which makes pumping work costly.

The use of vacuum pumping to lower the system pressure indicated less improvement in efficiency compared to the use of an oxygen scavenger in combination with sweep gassing (Fig. 12). This conclusion also held for the combination of the mechanical methods (sweep gassing + vacuum pumping, scheme (d)), where the same behavior as indicated in Fig. 13 was observed.

\subsection{Counterflow versus ideal mixing reactor configurations}

A counterflow arrangement represents a countercurrent flow between ceria and the gases which assumes that the gases are well mixed in the radial direction and only vary in the axial direction. The ideal mixing arrangement models a well-mixed reactor, resulting in no spatial variation of temperature, pressure, and species concentrations [34]. Compared to the counterflow arrangement, the ideal mixing arrangement required enormous amounts of sweep gas due to the need to maintain the whole reduction chamber at a low $p_{\mathrm{O}_{2}, 1}$. Owing to the large amount of
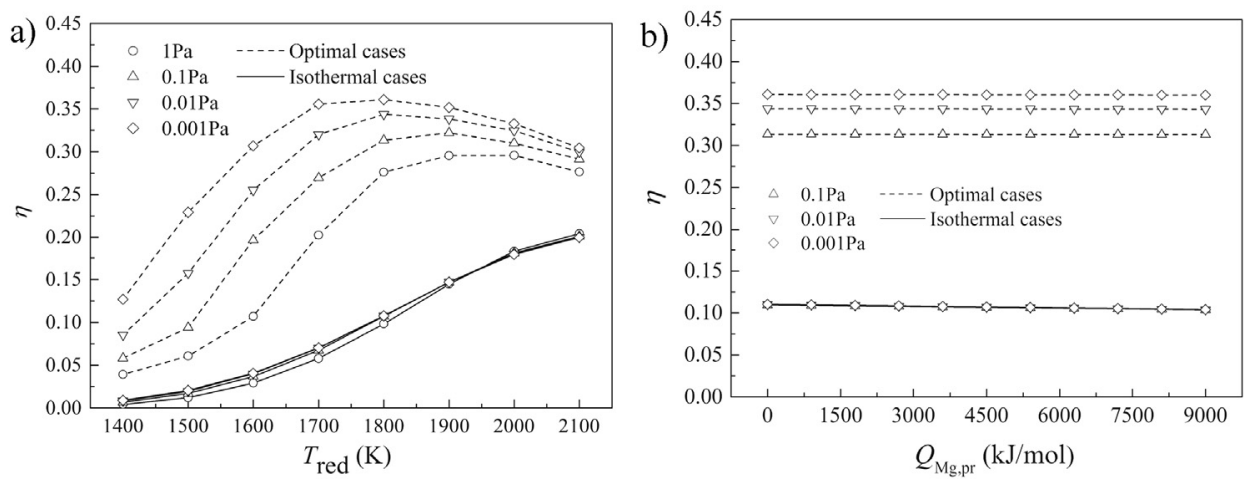

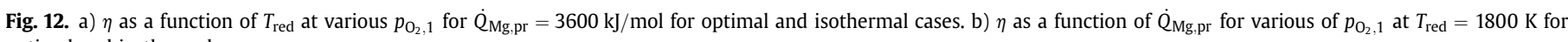
optimal and isothermal cases. 
sweep gas input, the previous studies utilizing ideal mixing arrangements $[14,17]$ predicted that larger $p_{\mathrm{O}_{2,1}}$ (of about $1000 \mathrm{~Pa}$ ) favor larger efficiencies and operation at large $\Delta T$ (to ensure a complete oxidation of ceria).

The efficiencies of schemes (a) and (b) at various operating conditions for an ideal mixing arrangement are shown in Figs. S2 to S6. Scheme (a) always worked at low efficiencies $(\eta<15 \%)$ and favored isothermal operation. The small efficiencies were caused by the large sweep gas and water input flow rates, respectively, which dominated the energy demand (Fig. S3). Scheme (b) showed efficiencies significantly larger than for scheme (a) due to a large decrease in the energy consumption to keep the $p_{\mathrm{O}_{2}, 1}$ in the reduction chamber low. Compared to the counterflow arrangement, the ideal mixing model tended to inefficiently use the water inflow and requires more sweep gas input, all of which led to significant lower efficiencies. The effect of changing $\varepsilon_{\mathrm{g}}$ on the system performance is shown in Fig. S5. As for the counterflow arrangement, for scheme (a) at isothermal conditions and in ideal mixing arrangement, larger $\varepsilon_{\mathrm{g}}$ resulted in larger efficiencies. This increase became more significant for $\varepsilon_{\mathrm{g}}>0.9$. Isothermal operation was favored in the ideal mixing arrangement as the reduction in $\dot{Q}_{\text {gas,red }}$ with increasing $\Delta T$ was to small to overcome the increase in $Q_{\text {ceria }}$ and $\dot{Q}_{\text {gas ox }}$ (Fig. S3c). Similar behavior in efficiency variation was observed for scheme (b) for the ideal mixing arrangement. However, scheme (b) could achieve larger efficiencies than scheme (a) as vacuum pumping required less energy than sweep gassing to maintain a low-oxygen atmosphere in the reaction chamber.

The influence of $\varepsilon_{\mathrm{S}}$ on the solar-to fuel efficiency is shown in Fig. S6a, and indicated negligible impact on scheme (a) in an ideal mixing arrangement due to the extremely low ceria flow rates. For scheme (b), the increase of $\varepsilon_{\mathrm{S}}$ led to higher efficiencies. However, this increase was small for large $\Delta T$ (Fig. S6b) due to the decreasing $\dot{Q}_{\text {ceria }}$ resulting from the decreasing ceria flow rate.

Generally, the ideal mixing arrangement is inferior to counterflow arrangement for schemes (a) and (b) because of significantly lower water utilization and the requirement of extremely large rates of sweep gas.

\section{Summary and conclusions}

A thermodynamic analysis was developed based on $[13,14,17]$ to evaluate the solar fuel processing performance of a ceria-based thermochemical cycling scheme at various working conditions. Mechanical and chemical methods for the decrease of the oxygen partial pressure in the reduction chamber were proposed, compared, and combined. The impact of flow arrangement in the reactors (counterflow versus ideal mixing), temperature, pressure, solid and gas heat recovery effectiveness, and concentration ratio were discussed. Both isothermal and non-isothermal operation for ceria based redox cycles were studied to find the optimal configurations for best solar-to-fuel efficiency.

For the scheme using sweep gassing to reduce $p_{\mathrm{O}_{2}, 1}$ (scheme (a)), the non-isothermal operation predicted significant higher efficiency than isothermal operation even without solid phase heat recover. The optimal temperature difference between the reduction and oxidation temperature was in the range of $100 \mathrm{~K}-150 \mathrm{~K}$ and this slight temperature difference between reduction and oxidation reactions ensured a high solar-to-fuel efficiency trading off the energy consumption caused by solid phase heating and recycling of large amounts of sweep gas.

For the scheme using vacuum pumping to reduce $p_{\mathrm{O}_{2}, 1}$ (scheme (b)), the optimal efficiencies were obtained at isothermal operation, indicating a promising way to conduct isothermal operation bearing both high efficiency as well as simple design and operation. The efficiency of the vacuum pump was crucial in dictating a high efficiency and was predicted to be around $40 \%$ throughout the operational range.

The gas phase heat recovery significantly increased the efficiency for sweep gassing and vacuum pumping schemes. A minimum $\varepsilon_{\mathrm{g}}$ of 0.9 was required for efficiencies of $25 \%$ for both scheme (a) and scheme (b), working at conditions leading to the optimal efficiency. The requirement for $\varepsilon_{\mathrm{g}}$ could be relaxed by imposing a small $\Delta T$ (of around $100-200 \mathrm{~K}$ ) with minimal efficiency reduction (below $3 \%$ when reducing $\varepsilon_{\mathrm{g}}$ from 0.975 to 0.9 ) for scheme (a) and scheme (b). The addition of solid phase heat recovery could further increase the efficiency. However, the absence of solid heat recovery didn't show a detrimental effect on the efficiency (efficiency reduction of $13.9 \%$ (scheme (a)) and $0.4 \%$ (scheme (b)) when changing $\varepsilon_{\mathrm{S}}$ from 1 to 0 at $T_{\mathrm{red}}=1800 \mathrm{~K}$ and $p_{\mathrm{O}_{2}, 1}=1 \mathrm{~Pa}$ ).

$\mathrm{A}$ high irradiation concentration led to lower radiation heat losses due to a reduced aperture area at the same solar energy input. The heat losses were dominating at large working temperatures due to the rapid increase of the radiation loss. The enhancement of the efficiency by increasing the concentration ratio became insignificant for concentrations above 5000 .

A novel scheme combining mechanical approaches (sweep gassing) and chemical approaches (chemical scavenger) to reduce the oxygen partial pressures showed promise in further increasing the system efficiency at non-isothermal conditions. The energy penalty caused by using active metal was in a reasonable range (below $0.5 \%$ of input energy for optimal cases of scheme (c)) as the amount of required sweep gas was minimized at non-isothermal conditions. Consequently, the combination of sweep gassing with a chemical scavenger provided a significant jump in efficiency from $28 \%$ to $36 \%$ for optimal cases at $1800 \mathrm{~K}$. For isothermal operation, the combined mechanical-chemical approach showed no enhancement effected by the large amount of required sweep gas. The combination of sweep gas, vacuum pumping, and a chemical oxygen scavenger could further improve the system efficiency, but less efficient as solely combining sweep gassing with an oxygen scavenger.

The counterflow and ideal mixing arrangement for fluid flow in reactor were implemented and compared. Generally speaking, the ideal mixing model is inferior to counterflow due to its inefficient use of sweep gas leading to extreme energy consumption in sweep gas heating, i.e. the maximum solar-to-fuel efficiency achieved for counter flow and ideal mixing arrangement was $18.2 \%$ and $4.3 \%$, respectively, at $T_{\text {red }}=1800 \mathrm{~K}$ and $p_{\mathrm{O}_{2}, 1}=10 \mathrm{~Pa}$.

The developed thermodynamic model of ceria-based cycling for solar fuel processing offers guidelines for the design and operation of redox cycles for solar fuel processing and can straightforward be applied to other promising redox materials such as perovskites [35-37].

\section{Acknowledgments}

We acknowledge the funding from the European Union's Seventh Framework Programme (FP7/2007-2013) for the Fuel Cells and Hydrogen Joint Technology Initiative under grant agreement number 621173. We acknowledge the Chinese scholarship council for supporting Meng Lin's PhD work. We thank Roman Bader from the Australian National University for fruitful discussion of the thermodynamic model. We thank Stefan Brendelberger from the Deutsche Luft und Raumfahrt Zentrum for discussion about pump efficiencies.

\section{Nomenclature}

A area $\left(\mathrm{m}^{-2}\right)$

$c_{p} \quad$ specific heat capacity $\left(\mathrm{J} \mathrm{mol}^{-1} \mathrm{~K}^{-1}\right)$ 
C

concentration ratio

$G_{0} \quad$ direct normal irradiance $\left(\mathrm{W} \mathrm{m}^{-2}\right)$

HHV higher heating value $\left(\mathrm{J} \mathrm{mol}^{-1}\right)$

$\chi_{\mathrm{H}_{2}} \quad$ hydrogen productivity

$f \quad$ heat loss factor

$f_{\mathrm{w}} \quad$ water utilization factor

$h \quad$ molar enthalpy $\left(\mathrm{J} \mathrm{mol}^{-1}\right)$

$\dot{n} \quad$ molar flow rate $\left(\mathrm{mol} \mathrm{s}^{-1}\right)$

$p \quad$ pressure $(\mathrm{Pa})$

$\dot{Q} \quad$ heat rate $(\mathrm{W})$

$R \quad$ universal gas constant $\left(8.3145 \mathrm{~J} \mathrm{~mol}^{-1} \mathrm{~K}^{-1}\right)$

$T \quad$ temperature (K)

W work rate $(\mathrm{W})$

Greek

$\Delta g \quad$ Gibbs free energy of formation $\left(\mathrm{J} \mathrm{mol}^{-1}\right)$

$\Delta h \quad$ enthalpy of formation $\left(\mathrm{J} \mathrm{mol}^{-1}\right)$

$\Delta s \quad$ entropy of reaction $\left(\mathrm{J} \mathrm{mol}^{-1} \mathrm{~K}^{-1}\right)$

$\Delta \delta \quad$ non-stoichiometric coefficient difference

$\delta \quad$ non-stoichiometric coefficient

$\varepsilon \quad$ heat recovery effectiveness

$\eta \quad$ solar-to-fuel efficiency

\section{Subscripts}

0 ambient

$1,2, \ldots$ state point

ap aperture

cool cooling

g gas

in inlet

$\mathrm{Mg}$ magnesium

ox oxidation

pump pumping

pr production

rad radiation

red reduction

react reaction

scavenger chemical scavenger

\section{Appendix A. Supplementary data}

Supplementary data related to this article can be found at http:// dx.doi.org/10.1016/j.energy.2015.06.006.

\section{References}

[1] Steinfeld A. Solar thermochemical production of hydrogen--a review. Sol Energy 2005;78:603-15. http://dx.doi.org/10.1016/j.solener.2003.12.012.

[2] Bicakova O, Straka P. Production of hydrogen from renewable resources and its effectiveness. Int J Hydrogen Energy 2012;37:11563-78. http://dx.doi.org/ 10.1016/j.ijhydene.2012.05.047.

[3] Abanades S, Flamant G. Thermochemical hydrogen production from a twostep solar-driven water-splitting cycle based on cerium oxides. Sol Energy 2006;80:1611-23.

[4] Kodama T. High-temperature solar chemistry for converting solar heat to chemical fuels. Prog Energy Combust Sci 2003;29. http://dx.doi.org/10.1016 S0360-1285(03)00059-5.

[5] Perkins C, Weimer AW. Likely near-term solar-thermal water splitting technologies. Int J Hydrogen Energy 2004;29:1587-99. http://dx.doi.org/10.1016 j.ijhydene.2004.02.019.

[6] KOGAN A. Direct solar thermal splitting of water and on site separation of the products I. Theoretical evaluation of hydrogen yield. Int J Hydrogen Energy 1997;22:481-6. http://dx.doi.org/10.1016/S0360-3199(96)00125-5.

[7] Perkins C, Weimer AW. Solar-thermal production of renewable hydrogen. AIChE J 2009;55:286-93.

[8] Abanades S, Charvin P, Flamant G, Neveu P. Screening of water-splitting thermochemical cycles potentially attractive for hydrogen production by concentrated solar energy. Energy 2006;31:2469-86. http://dx.doi.org/ 10.1016/j.energy.2005.11.002.
[9] Kodama T, Gokon N. Thermochemical cycles for high-temperature solar hydrogen production. Chem Rev 2007;107:4048-77.

[10] Pregger T, Graf D, Krewitt W, Sattler C, Roeb M, Möller S. Prospects of solar thermal hydrogen production processes. Int J Hydrogen Energy 2009;34: 4256-67. http://dx.doi.org/10.1016/j.ijhydene.2009.03.025.

[11] Siegel NP, Miller JE, Ermanoski I, Diver RB, Stechel EB. Factors affecting the efficiency of solar driven metal oxide thermochemical cycles. Ind Eng Chem Res 2013;52:3276-86.

[12] Chueh WC, Haile SM. A thermochemical study of ceria: exploiting an old material for new modes of energy conversion and $\mathrm{CO}_{2}$ mitigation. Philos Trans R Soc A Math Phys Eng Sci 2010;368:3269-94. http://dx.doi.org/10.1098/ rsta.2010.0114.

[13] Bader R, Venstrom LJ, Davidson JH, Lipiński W. Thermodynamic analysis of isothermal redox cycling of ceria for solar fuel production. Energy Fuels 2013;27:5533-44. http://dx.doi.org/10.1021/ef400132d.

[14] Lapp J, Davidson JH, Lipinski W, Lipiński W. Efficiency of two-step solar thermochemical non-stoichiometric redox cycles with heat recovery. Energy 2012;37:591-600. http://dx.doi.org/10.1016/j.energy.2011.10.045.

[15] Chueh WC, Haile SM. Ceria as a thermochemical reaction medium for selectively generating syngas or methane from $\mathrm{H}_{2} \mathrm{O}$ and $\mathrm{CO}_{2}$. ChemSusChem 2009;2:735-9.

[16] Hao Y, Yang C-K, Haile SM. High-temperature isothermal chemical cycling for solar-driven fuel production. Phys Chem Chem Phys 2013;15:17084-92.

[17] Ermanoski I, Siegel NP, Stechel EB. A new reactor concept for efficient solarthermochemical fuel production. J Sol Energy Eng 2013;135:31002.

[18] Chueh WC, Falter C, Abbott M, Scipio D, Furler P, Haile SM, et al. High-flux solar-driven thermochemical dissociation of $\mathrm{CO}_{2}$ and $\mathrm{H}_{2} \mathrm{O}$ using nonstoichiometric ceria. Science 2010;330:1797-801. http://dx.doi.org/10.1126/ science. 1197834

[19] Furler P, Sche J, Gorbar M, Moes L, Vogt U, Steinfeld A. Solar thermochemical $\mathrm{CO}_{2}$ splitting utilizing a reticulated porous ceria redox system. 2012.

[20] Furler P, Scheffe J, Marxer D, Gorbar M, Bonk A, Vogt U, et al. Thermochemical $\mathrm{CO}_{2}$ splitting via redox cycling of ceria reticulated foam structures with dualscale porosities. Phys Chem Chem Phys 2014:16:10503-11.

[21] Furler P, Scheffe JR, Steinfeld A. Syngas production by simultaneous splitting of $\mathrm{H}_{2} \mathrm{O}$ and $\mathrm{CO}_{2}$ via ceria redox reactions in a high-temperature solar reactor. Energy Environ Sci 2012;5:6098-103.

[22] Roeb M, Sattler C. Isothermal water splitting. Sci (80-) 2013;341:470-1. http://dx.doi.org/10.1126/science.1241311.

[23] Muhich CL, Evanko BW, Weston KC, Lichty P, Liang XH, Martinek J, et al. Efficient generation of $\mathrm{H}-2$ by splitting water with an isothermal redox cycle. Sci (80-) 2013;341:540-2. http://dx.doi.org/10.1126/science.1239454.

[24] Lundberg M. Model calculations on some feasible two-step water splitting processes. Int J Hydrogen Energy 1993;18:369-76.

[25] Panlener RJ, Blumenthal RN, Garnier JE. A thermodynamic study of nonstoichiometric cerium dioxide. J Phys Chem Solids 1975;36:1213-22.

[26] Riess I, Ricken M. On the specific heat of nonstoichiometric ceria. J Solid State Chem 1985:57:314-22.

[27] Pai BC, Ramani G, Pillai RM, Satyanaryana KG. Role of magnesium in cast aluminium alloy matrix composites. J Mater Sci 1995;30:1903-11.

[28] Dulski TR. Trace elemental analysis of metals: methods and techniques. CRC Press; 1999.

[29] Wulandari W, Brooks GA, Rhamdhani MA, Monaghan BJ. Magnesium: current and alternative production routes. In: Chemeca 2010 Eng Edge; 26-29 Sept 2010, Hilt Adelaide, South Aust; 2008. p. 347.

[30] Charvin P, Stéphane A, Florent L, Gilles F. Analysis of solar chemical processes for hydrogen production from water splitting thermochemical cycles. Energy Convers Manag 2008;49:1547-56. http://dx.doi.org/10.1016/j.enconman. 2007.12.011.

[31] Cherubini F, Raugei M, Ulgiati S. LCA of magnesium production. Resour Conserv Recycl 2008;52:1093-100. http://dx.doi.org/10.1016/j.resconrec. 2008.05.001.

[32] Brendelberger S, Sattler C. Concept analysis of an indirect particle-based redox process for solar-driven $\mathrm{H}_{2} \mathrm{O} / \mathrm{CO}_{2}$ splitting. Sol Energy 2015;113:158-70. http://dx.doi.org/10.1016/j.solener.2014.12.035.

[33] Gratz ES, Guan X, Milshtein JD, Pal UB, Powell AC. Mitigating electronic current in molten flux for the magnesium SOM process. Metall Mater Trans B 2014;45:1-12. http://dx.doi.org/10.1007/s11663-014-0060-9.

[34] Rawlings JB, Ekerdt JG. Chemical reactor analysis and design fundamentals. Nob Hill Pub, Llc; 2002.

[35] Yang C-K, Yamazaki Y, Aydin A, Haile SM. Thermodynamic and kinetic assessments of strontium-doped lanthanum manganite perovskites for twostep thermochemical water splitting. J Mater Chem A 2014;2:13612. http:// dx.doi.org/10.1039/C4TA02694B.

[36] Nalbandian L, Evdou A, Zaspalis V. La1-xSrxMO3 ( $\mathrm{M}=\mathrm{Mn}, \mathrm{Fe})$ perovskites as materials for thermochemical hydrogen production in conventional and membrane reactors. Int J Hydrogen Energy 2009;34:7162-72. http:// dx.doi.org/10.1016/j.ijhydene.2009.06.076.

[37] Evdou a, Nalbandian L, Zaspalis VT. Perovskite membrane reactor for continuous and isothermal redox hydrogen production from the dissociation of water. J Memb Sci 2008;325:704-11. http://dx.doi.org/10.1016/j.mem sci.2008.08.042. 